
Maldonado Rafael (Orcid ID: 0000-0002-4359-8773)

\section{Sigma-1 receptor modulates neuroinflammation associated with mechanical hypersensitivity and opioid tolerance in a mouse model of osteoarthritis pain}

Running title: $\sigma 1 \mathrm{R}$ on mechanical pain and opioid tolerance during osteoarthritis

Mireia Carcolé ${ }^{1}$, Sami Kummer ${ }^{1}$, Leonor Gonçalves ${ }^{3}$, Daniel Zamanillo², Manuel Merlos ${ }^{2}$, Anthony H. Dickenson $^{3}$, Begoña Fernández-Pastor ${ }^{2}$, David Cabañero ${ }^{1 *}$, Rafael Maldonado ${ }^{1 *}$

${ }^{1}$ Neuropharmacology Lab, Department of Experimental and Health Sciences, University Pompeu Fabra, c/ Dr. Aiguader 88, 08003, Barcelona, Spain

${ }^{2}$ Drug Discovery and Preclinical Development, Laboratories Esteve. Barcelona Science Park, c/ Baldiri Reixac 10, 08028, Barcelona, Spain

${ }^{3}$ University College London, Gower Street, Department of Neuroscience, Physiology and Pharmacology, London, WC1E 6BT, UK

*These authors contributed equally

Corresponding author: Rafael Maldonado López (rafael.maldonado@upf.edu)

Word count: Abstract (247), Main text (4108).

№ pages of the manuscript: 39

№ figures: 7

\section{Bullet point summary}

What is already known?

- $\sigma 1 R$ antagonists modulate mu-opioid receptor activity and acutely alleviate inflammatory and neuropathic pain.

What this study adds?

This article has been accepted for publication and undergone full peer review but has not been through the copyediting, typesetting, pagination and proofreading process which may lead to differences between this version and the Version of Record. Please cite this article as doi: 10.1111/bph.14794 
- Repeated E-52862 promotes gradual normalization of mechanical sensitivity inhibiting neuroinflammation critical for osteoarthritis pain.

E-52862 antinociception involves the mu-opioid receptor and reverses morphine tolerance during chronic osteoarthritis pain.

Clinical significance

E-52862 could dampen opioid deleterious side effects and be an alternative for long-term treatments.

E-52862 provides acute and long-lasting pain-relieving effects during osteoarthritis pain.

\section{Acknowledgments}

We acknowledge the financial support of the European Commission (FP7, NeuroPain \#2013-602891), the Catalan Government (AGAUR, \#SGR2017-669), the Spanish Instituto de Salud Carlos III (RTA, \#RD16/0017/0020) and AGAUR (ICREA Academia Award 2015). MC is the recipient of an Industrial Doctorate contract from the Catalan Government and Laboratorios Esteve (AGAUR, \#2014-DI-040). Partial support from FEDER funds is also acknowledged.

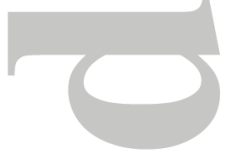

\section{Author contributions}

All authors listed above have contributed sufficiently to be included as authors. M.C. conducted the behavioural, electrophysiological and molecular experiments and wrote the manuscript. S.K. conducted the molecular studies. L.G. supervised all the electrophysiological experiments. D.Z. and M.M. participated in the experimental design. A.H.D. provided the electrophysiological equipment. B.F-P. supervised the project and participated in the experimental design. D.C. conceptualized and supervised the project, participated in the experimental design and wrote the manuscript. R.M. conceptualized, supervised and funded the project, participated in the experimental design and wrote the manuscript. All the authors have revised the work critically for important intellectual content and approved the final version to be published. 


\section{List of Hyperlinks for Crosschecking}

Sigma-1 receptor:

http://www.guidetopharmacology.org/GRAC/ObjectDisplayForward?objectld=2552

$\mu$-opioid receptor:

http://www.guidetopharmacology.org/GRAC/ObjectDisplayForward?objectld=319

Sigma-1 receptor antagonist E-52862:

http://www.guidetopharmacology.org/GRAC/LigandDisplayForward?ligandld=10431

Morphine:

http://www.guidetopharmacology.org/GRAC/LigandDisplayForward?ligandld=1627

Sigma-1 receptor agonist PRE-084:

http://www.guidetopharmacology.org/GRAC/LigandDisplayForward?ligandld=6678

Naloxone hydrochloride:

https://www.guidetopharmacology.org/GRAC/LigandDisplayForward?ligandld=1638

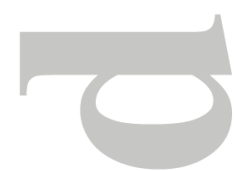

\section{Abstract}

Background and purpose: Osteoarthritis pain is a chronic disabling condition lacking effective treatment. Continuous use of opioid drugs during osteoarthritis pain induces tolerance and may result in dose escalation and abuse. Sigma-1 receptor $(\sigma 1 R)$, a chaperone expressed in key areas for pain control, modulates mu-opioid receptor (MOR) activity and represents a promising target to tackle these problems. The present study investigates the efficacy of $\sigma 1 R$ antagonist E-52862 to inhibit pain sensitization, morphine tolerance and associated electrophysiological and molecular changes in a murine model of osteoarthritis pain.

Experimental approach: Mice received an intra-knee injection of monoiodoacetate followed by 14day treatment with E-52862, morphine or vehicle, and mechanical sensitivity was assessed before and after the daily doses. 
Key results: Monoiodoacetate-injected mice developed persistent mechanical hypersensitivity, which was dose-dependently inhibited by E-52862. Interestingly, mechanical thresholds assessed before the daily E-52862 dose showed gradual recovery, reaching complete restoration by the end of the treatment. When repeated treatment started 15 days after knee injury, E-52862 produced enhanced short-term analgesia, but the recovery to baseline thresholds was slower. Interestingly, both a $\sigma 1 \mathrm{R}$ agonist and a MOR antagonist inhibited E-52862 analgesic effect, and an acute sub-effective E-52862 dose restored morphine analgesia in opioid-tolerant mice. Moreover, E-52862 abolished spinal sensitization in osteoarthritic mice and inhibited pain-related molecular changes.

Conclusion and implications: These findings show dual effects of $\sigma 1 R$ antagonism alleviating both short- and long-lasting antinociception during chronic osteoarthritis pain and identify E-52862 as a promising pharmacological agent to treat chronic pain and elude opioid tolerance.

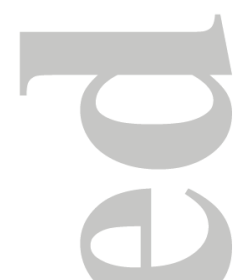

\section{Abbreviation list}

BDNF: Brain-derived neurotrophic factor

DRG: Dorsal root ganglia

IL1ß: Interleukin-1 beta

MIA: Monoiodoacetate

MOR: $\mu$-opioid receptor NPY: Neuropeptide Y

WDR: Wide dynamic range

б1R: Sigma-1 receptor

This article is protected by copyright. All rights reserved. 


\section{Keywords}

Sigma-1 receptor, osteoarthritis pain, mechanical allodynia, opioid tolerance, central sensitization, spinal cord neurons, neuroinflammation

\section{Introduction}

Osteoarthritis is the most frequent chronic musculoskeletal pain condition (Breivik et al., 2006), characterized by progressive destruction of articular cartilage (Sutton et al., 2009; Zhang et al., 2013). Pain is the major symptom of osteoarthritis and the reason for presentation of patients to clinical services. However, available therapeutic approaches do not control the progression of the disease and do not provide satisfactory analgesia (Wieland et al., 2005). Opioids are potent analgesics widely used for severe pain management. However prolonged administration has been associated with tolerance, abuse liability and hyperalgesia (Vowles et al., 2015). Long-term opioid prescriptions increased importantly over the last decade, mainly in USA, becoming a public health problem with devastating consequences including overdose-related deaths (Lyden and Binswanger, 2019). Therefore, there is an urgent need to develop safer therapeutic alternatives for chronic pain.

Sigma-1 receptor $(\sigma 1 \mathrm{R})$ is a ligand-regulated chaperone located mainly in the endoplasmic reticulum (Alonso et al., 2000). It has been proposed as an amplifier of signal transduction cascades that modulates a variety of receptors and ion channels (Su et al., 2010; Zamanillo et al., 2013). $\sigma 1 \mathrm{R}$ is expressed in areas of the nervous system crucial for pain transmission such as the dorsal root ganglia (DRG), dorsal horn and periaqueductal grey (Alonso et al., 2000; Bangaru et al., 2013). Behavioural studies showed its involvement in models of neuropathic and inflammatory pain (Romero et al., 2016). Osteoarthritis involves inflammatory and neuropathic pain mechanisms (Ivanavicius et al., 2007; Wylde et al., 2011) at distinct points of the disease (Arendt-Nielsen et al., 2010), but the role of $\sigma 1 \mathrm{R}$ 
in these different stages has not been yet investigated. Moreover, functional interactions have been reported between $\sigma 1 R$ and $\mu$-opioid receptor (MOR) (Kim et al., 2010). Indeed, $\sigma 1 R$ antagonists enhance opioid-induced analgesia in rodent models of acute nociception and inflammation (Chien and Pasternak, 1995; Vidal-Torres et al., 2013; Montilla-García et al., 2019), and did not potentiate opioidinduced side effects such as tolerance or physical dependence (Vidal-Torres et al., 2013), which could represent an important advantage for long-term opioid treatment. However, it is unknown if $\sigma 1 \mathrm{R}$ modulates opioid analgesia and tolerance during osteoarthritis chronic pain. Interestingly, $\sigma 1 \mathrm{R}$ is upregulated and redistributed from the endoplasmic reticulum to other subcellular locations under cellular stress (Hayashi and Su, 2007; Zamanillo et al., 2013), which is associated to chronic pain and morphine tolerance (Inceoglu et al., 2015; Liu et al., 2018). Hence, characterizing the role of $\sigma 1 \mathrm{R}$ on osteoarthritis pain and opioid tolerance could provide insight to improve the available therapeutic strategies.

This study investigates the role of $\sigma 1 R$ in the monoiodoacetate (MIA) mouse model of osteoarthritis pain and its participation on opioid tolerance. We assess the antinociceptive effects of acute and chronic treatment with $\sigma 1 \mathrm{R}$ antagonist E-52862 (also named S1RA (Romero et al., 2012) and MR309 (Castany et al., 2018)) and evaluate its effects in vivo on spinal electrophysiological recordings performed in animals with osteoarthritis pain. Involvement of MOR on the analgesic effects of E-52862 and its participation on morphine tolerance are also investigated. Pain and morphine-associated biochemical alterations are also investigated in spinal cord and DRG of mice with osteoarthritis pain. 


\section{Methods}

\subsection{Animal experimental conditions}

Swiss albino male mice (Charles River, Lyon, France) 8 to 12 weeks old were used in all the experiments. Mice weighted 22 to $24 \mathrm{~g}$ at the beginning of the experiments and were housed in groups of 3-4 with free access to water and food. Housing conditions were maintained at $21 \pm 1 \stackrel{\circ}{ } \mathrm{C}$ and $55 \pm$ $10 \%$ relative humidity in a controlled light/dark cycle (light on between 8:00 a.m. and 8:00 p.m.). All experimental procedures and animal husbandry were conducted following the ARRIVE guidelines and according to the ethical principles of the International Association for the Study of Pain (IASP) for the evaluation of pain in conscious animals (Zimmermann, 1986) and the European Parliament and the Council Directive (2010/63/EU), and were approved by the Animal Care and Use Committees of the PRBB and Departament de Territori I Habitatge of Generalitat de Catalunya. All experiments were performed under blind conditions.

\subsection{Intra-articular injection of monoiodoacetate}

Osteoarthritis pain was induced in mice briefly anaesthetized with isoflurane $(2 \% \mathrm{v} / \mathrm{v})$ vaporized in oxygen. The knee joint was shaved and flexed at a $90^{\circ}$ angle and $10 \mu \mathrm{l}$ of MIA ( $10 \mathrm{mg} / \mathrm{ml}$, Sigma Aldrich, UK) dissolved in sterile saline ( $\mathrm{NaCl} 0.9 \%)$ were injected into the joint space with a 30 -gauge needle, as previously described (Negrete et al., 2017). Sham mice received the same volume of sterile saline.

\subsection{Nociceptive behaviour}

Hypersensitivity to punctate stimuli (which will be referred as mechanical allodynia) was used as outcome measure of osteoarthritis pain by measuring the hind paw withdrawal response to von Frey filaments stimulation (Chaplan et al., 1994). Briefly, animals were placed in Plexiglas cylinders $(20 \mathrm{~cm}$ high, $9 \mathrm{~cm}$ diameter) positioned on a grid surface through which calibrated von Frey filaments (North Coast Medical, USA) were applied following the up-down paradigm as previously reported (Chaplan et al., 1994). The 0.4-g filament was used first, and the strength of the next filament was decreased or 
increased according to the response following this sequence $0.07,0.16,0.4,0.6,1,2 \mathrm{~g}$. The $2-\mathrm{g}$ filament was used as a cutoff. The mechanical threshold (in grams) was then calculated by the updown Excel program (Dixon, 1965). Animals were habituated for $1 \mathrm{~h}$ before testing to allow an appropriate behavioural immobility. Clear paw withdrawal, shaking or licking was considered as nociceptive response. Both ipsilateral and contralateral hind paws were tested. Only ipsilateral responses are shown since contralateral sides showed no significant alteration of the mechanical thresholds. The percentage of inhibition of mechanical nociception for the dose-response curves was calculated based on the hypersensitivity before the drug administration ( $0 \%)$ and the maximal possible mechanical thresholds (100\%).

2.4. Drug preparation

The selective $\sigma 1 \mathrm{R}$ antagonist E-52862 (4-(2-[5-methyl-1-(naphthalen-2-yl)-1H-pyrazol-3-yloxy]ethyl) morpholine) and the MOR agonist morphine were dissolved in an aqueous solution $(0.5 \%$ hydroxypropylmethyl cellulose, HPMC) and were administered by the intraperitoneal route (i.p.) at a volume of $10 \mathrm{ml} / \mathrm{kg} 30 \mathrm{~min}$ before behavioural testing. For spinal electrophysiological recordings, the doses of E-52862 were selected based on previous studies showing antinociceptive effects after intrathecal administration (Vidal-Torres et al., 2014). The $\sigma 1 \mathrm{R}$ agonist PRE-084 ([2-(4morpholinethyl)1-phenylcyclohexanecarboxylate]) and naloxone hydrochloride were diluted in physiological saline ( $0.9 \%$ sodium chloride) and were administered subcutaneously (s.c.) at a volume of $5 \mathrm{ml} / \mathrm{kg}, 5 \mathrm{~min}$ before $\mathrm{E}-52862$.

\subsection{In vivo spinal cord electrophysiology}

In vivo electrophysiology was performed 13-17 days following MIA/sham injection. Animals were anaesthetized with $3.5 \% \mathrm{v} / \mathrm{v}$ isofluorane delivered in $3: 2$ ratio of nitrous oxide and oxygen and were maintained on $1.5 \% \mathrm{v} / \mathrm{v}$ for the whole duration of the experiment (approximately $5-7 \mathrm{~h}$ ), core body temperature was regulated with a homeothermic blanket and respiratory rate was visually monitored. 
Mice were secured in a stereotaxic frame and a laminectomy was performed exposing L3-L5 of the spinal cord. Extracellular recordings were performed using $127 \mu \mathrm{m}$ diameter parylene-coated tungsten electrodes. Single wide dynamic range (WDR) neurons receiving inputs from the hind paw were isolated in the ipsilateral dorsal horn, and the receptive field was then stimulated using a wide range of stimuli: brush, von Frey filaments $[0.16,0.4,0.6,1,2,4,6,8,15,26,60$ g], static pressure [pinch] and heat [48드 applied over a period of $10 \mathrm{sec}$ per stimulus. Stimuli were applied starting with the stimulus of lowest intensity in the following order: brush, von Frey, pressure and heat. One-2 WDR cells were isolated from each animal, and the average response was calculated. A sample size of 6-8 animals per group was obtained except for the sham group where only 4 animals could be recorded due to casualties during the process of neuron isolation, where animals are maintained under anaesthesia for long periods of time.

Baseline recordings were made with $15 \mu$ l vehicle ( $0.9 \%$ saline) applied to the dorsal part of the spinal cord. After obtaining 3 to 4 baseline responses (with 5 min between each set of trials, data were averaged to obtain control values), the vehicle was removed and 90 and $180 \mu \mathrm{g}$ E-52862 diluted in saline were applied to the spinal cord in a volume of $15 \mu \mathrm{l}$. Firing frequency was recorded 10 and 30 min after application of the drug. All mice were terminally anesthetized with isoflurane after the experiment. Data were captured and analysed using a CED 1401 interface coupled to a computer running Spike 2 software.

\subsection{Tissue isolation}

Mice were euthanized by cervical dislocation 1 or 15 days after sham or osteoarthritis induction. The dorsal lumbar region of the spinal cord and L3-L5 DRG ipsilateral to the side of the knee injection were rapidly isolated. Tissues were fresh frozen and stored at $-80^{\circ} \mathrm{C}$ until use.

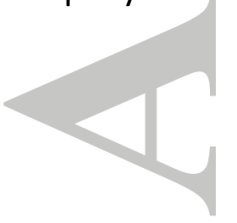




\subsection{Immunoblot analysis}

Immunoblots have been conducted complying the BJP guidelines (Alexander et al., 2018). Frozen tissues were processed to obtain the total solubilized fraction, as previously described (Ozaita et al., 2007). Briefly, tissues were dounce-homogenized in 30 volumes of lysis buffer $(50 \mathrm{mmol} / \mathrm{l} \mathrm{Tris-HCl} \mathrm{pH}$ 7.4, $150 \mathrm{mmol} / \mathrm{I} \mathrm{NaCl}, 10 \%$ glycerol, $1 \mathrm{mmol} / / \mathrm{EDTA}, 1 \mu \mathrm{g} / \mathrm{ml}$ aprotinin, $1 \mu \mathrm{g} / \mathrm{ml}$ leupeptine, $1 \mu \mathrm{g} / \mathrm{ml}$ pepstatin, $1 \mathrm{mmol} / \mathrm{l}$ sodium fluoride, $5 \mathrm{mmol} / \mathrm{l}$ sodium pyrophosphate and $40 \mathrm{mmol} / \mathrm{l}$ betaglycerolphosphate) with $1 \%$ Triton $\mathrm{X}-100$. After $10 \mathrm{~min}$ of incubation at $4 \stackrel{\circ}{ } \mathrm{C}$, samples were centrifuged at $16000 \mathrm{~g}$ for $30 \mathrm{~min}$ to remove insoluble debris. Protein contents in the supernatants were determined by DC-micro plate assay following manufacturer's instructions. Blots containing equal amounts of protein samples were probed for different primary antibodies: anti-lba1 (1:500), anti-GluR2 (1:2000), anti-phosphoNR1 (1:500), anti-NR1 (1:2000), anti-phosphoNR2B (1:500), antiNR2B (1:1000), anti-mGluR5 (1:2000), and anti-glyceraldehyde-3-phosphate dehydrogenase (GAPDH) (1:10000), and anti-Actin (1:10000). Bound primary antibodies were detected using horseradish peroxidase-conjugated antibodies to rabbit (1:2000) or mouse antibodies (1:2000) and visualized by enhanced chemiluminescence detection (Clarity Western ECL Substrate). When necessary, Immobilon-P membranes were stripped in buffer containing $62.5 \mathrm{mM}$ Tris $\mathrm{pH} 6.5,2 \%$ SDS (vol/vol) and $0.1 \mathrm{M}$ beta-mercaptoethanol ( $\mathrm{vol} / \mathrm{vol}$ ) for $30 \mathrm{~min}$ at $37{ }^{\circ} \mathrm{C}$, followed by extensive washing in $100 \mathrm{mM}$ $\mathrm{NaCl}, 10 \mathrm{mM}$ Tris and $0.1 \%$ Tween $20(\mathrm{pH} \mathrm{7.4)}$ before re-blocking and re-probing. The optical density of the relevant immunoreactive bands was quantified after acquisition on a ChemiDoc MP Imaging System controlled by Image Lab Touch Software. For quantitative purposes, the optical density values of phospho-specific antibodies were normalized to the detection of nonphospho antibodies in the same sample, and GAPDH or Actin were used as the housekeeping control. Data were expressed as a fold change of the control sham-vehicle group.

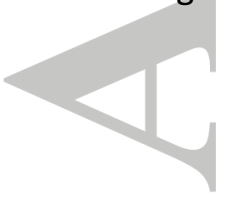

This article is protected by copyright. All rights reserved. 


\subsection{Gene expression analysis by real-time PCR}

Total RNA was isolated from frozen $\left(-80^{\circ} \mathrm{C}\right)$ spinal cords and DRG with TRIzol reagent plus RNA purification kit and subsequently retrotranscribed to cDNA with the High-capacity cDNA reverse transcription kit. Gene expression of neuropeptide Y (NPY), brain derived neurotrofic factor (BDNF), tumor necrosis factor $\alpha$ (TNF $\alpha)$ and Interleukin-1 $\beta$ (IL1 $\beta)$ in both tissues obtained 1 and 15 days after MIA injection was assessed by real-time PCR. Quantitative analysis of gene expression was measured with TaqMan Gene Expression assays "Mm01410146_m1" for NPY, "Mm01334043_m1" for BDNF, "Mm00443258_m1" for TNF $\alpha$, and "Mm00434228_m1" for IL1 $\beta$ as a double-stranded DNA-specific fluorescent dye and performed on the ABI Prism 7900 HT. HPRT was used as housekeeping gene, detected with TaqMan gene expression assay "Mm00446968_m1". Data for each target gene were normalized to HPRT, and the fold change in target gene mRNA abundance was determined by the $2^{(-}$ ${ }^{\Delta \Delta C t)}$ method (Livak and Schmittgen, 2001).

\subsection{Data and statistical analysis}

The data and statistical analysis comply with the recommendations on experimental design and analysis in pharmacology (Curtis et al., 2018). Sample size was based on previous behavioural studies with similar number of factors under the same experimental conditions that achieved statistically significant results (Gris et al., 2014; Negrete et al., 2017). Mice were randomly assigned to each surgery and/or treatment group, generating groups with similar initial number of animals for each experiment. The minor variations in the final number among the groups in each experiment are due to the loss of 1 to 2 animals during the whole experimental sequence mainly as a result of surgical procedures and subsequent consequences. Animals showing behavioural abnormalities after surgical procedures were euthanized following the ethical committee criteria. Animal casualties during the electrophysiological recordings were higher, and a group of 4 mice was obtained, which was not subjected to statistical analysis. Outliers were not excluded, and the declared group size is the number of independent values. A 3-way repeated measure analysis of variance (ANOVA) with "surgery" as between factor and "day" 
and "pre vs. post" as within-subject factors was used to analyse von Frey data during chronic treatment. To analyse the differences between early vs. late treatments and pre vs post values, the slopes of the regression lines were calculated for each animal and the average slope for each group. Afterwards, a 2-way ANOVA was used with "early vs late" as between factor and "pre vs post" as within-subject factor. For von Frey assessment on day 14 before and after acute treatments, a 2-way repeated measures ANOVA was used, with "treatment" as between-subjects factor and "pre vs. post" as within-subject factor. For dose-response curves, an F-test was used to compare the non-linear regression fittings. Electrophysiological data was analysed with an F-test to compare non-linear regressions and a 2-way repeated measure ANOVA ("surgery" as between-subject factor and "stimulus" as within-subject factor). A 2-way ANOVA ("surgery" and "treatment") was used to analyse data from molecular studies. In all comparisons, Fisher Least Significant Difference (LSD) post hoc analysis was applied when appropriate (significant interaction between factors). STATISTICA 6.0 software was used. The differences were considered statistically significant when the P value was below 0.05 .

\subsection{Materials}

The selective $\sigma 1 \mathrm{R}$ antagonist E-52862 (4-(2-[5-methyl-1-(naphthalen-2-yl)-1H-pyrazol-3-yloxy]ethyl) morpholine), and the $\sigma 1 \mathrm{R}$ agonist PRE-084 ([2-(4-morpholinethyl)1-phenylcyclohexanecarboxylate]) were developed and supplied by Laboratories Esteve (Barcelona, Spain). The MOR agonist morphine hydrochloride was obtained from the General Directorate of Pharmacy and Drugs, Spanish Ministry of Health (Madrid, Spain), and the MOR antagonist naloxone hydrochloride was purchased from SigmaAldrich (Saint Louis, United States). HPMC was obtained from Sigma Aldrich (Saint Louis, United States). For the electrophysiological study, parylene-coated tungsten electrodes from A-M Systems (Sequim, United States) and Spike 2 software from Cambridge Electronic Design (Cambridge, United Kingdom, RRID: SCR_000903) were used. DC-micro plate assay was purchase from Bio-Rad (Hercules, United States), and Immobilon-P membranes from Merck Millipore (Burlington, United States; Cat\# 
IPVH09120). In the molecular studies, the following antibodies were used: anti-lba1 (Wako Pure Chemical Industries, Osaka, Japan; Cat\# 016-20001, RRID: AB_839506), anti-GluR2 (Merck Millipore, Burlington, United States; Cat\# AB1768, RRID: AB_2313802), anti-phosphoNR1 (Cell signalling, Danvers, United States; Cat\# 3381, RRID: AB_2294781), anti-NR1 (Novus biologicals, Centennial, United States; Cat\# NB300-118, RRID: AB_10002447), anti-phosphoNR2B (Sigma Aldrich, Saint Louis, United States; Cat\# M2442, RRID: AB_262150), anti-NR2B (Merck Millipore, Burlington, United States; Cat\# AB1557P, RRID: AB_90772), anti-mGluR5 (Merck Millipore, Burlington, United States; Cat\# AB5675, RRID: AB_2295173), anti-GAPDH (Santa Cruz Technologies, Dallas, United States; Cat\# sc32233, RRID: AB_627679), anti-Actin (Sigma Aldrich, Saint Louis, United States; Cat\# A5441, RRID: AB_476744), anti-rabbit (Cell signalling, Danvers, United States; Cat\# 7074, RRID: AB_2099233) and anti-mouse (Santa Cruz Technologies, Dallas, United States; Cat\# sc-2005, RRID: AB_631736). The optical density of the relevant immunoreactive bands was visualized using Clarity Western ECL Substrate (Cat\# 1705061) and the ChemiDoc MP Imaging System from Bio-Rad (Hercules, United States). For the gene expression analysis by real-time PCR, the following reagents were used: TRIzol reagent plus RNA purification kit from Ambion (Waltham, United States; Cat\# AM1924), and Highcapacity cDNA reverse transcription kit (Cat\# 4368814), TaqMan Gene Expression assays and ABI Prism 7900 HT from Applied Biosystems (Waltham, United States). The statistical analysis was performed with the STATISTICA 6.0 software was used (StatSoft, Inc., Tulsa, United States, RRID: SCR_014213).

\subsection{Nomenclature of Targets and Ligands}

Key protein targets and ligands in this article are hyperlinked to corresponding entries in http://www.guidetopharmacology.org, the common portal for data from the IUPHAR/BPS Guide to PHARMACOLOGY (Harding et al., 2018), and are permanently archived in the Concise Guide to PHARMACOLOGY 2017/18 (Alexander et al., 2017a, 2017b).

This article is protected by copyright. All rights reserved. 


\section{Results}

\subsection{The $\sigma 1 R$ antagonist E-52862 produces acute antinociception and a gradual normalization of}

mechanical sensitivity during osteoarthritis pain

To assess the therapeutic potential of E-52862 in chronic osteoarthritis pain, we evaluated its effects on mechanical allodynia in mice subjected to joint pain induced by MIA. Mice received vehicle or different i.p. E-52862 doses (5-10-20 mg/kg) twice a day during 14 days, starting the first day after MIA or sham injection. Mechanical thresholds were measured before (PRE values) and 30 min after (POST) the first daily administration (Fig. 1A). Baseline mechanical thresholds were similar in all groups and sham animals did not show nociceptive changes along the experiment regardless of the treatment (Fig. 1B-1G). Intra-knee MIA injection led to a marked decrease of withdrawal thresholds to mechanical stimuli when compared to sham. Mechanical allodynia was shown from the first day after MIA until the end of the experiment in vehicle-treated mice (Fig. 1B, 1F). Acute E-52862 doses of 5 and $10 \mathrm{mg} / \mathrm{kg}$ were sub-effective, whereas $20 \mathrm{mg} / \mathrm{kg}$ clearly alleviated MIA-induced hypersensitivity, demonstrating dose-dependent analgesic effects of E-52862 after single administration (POST values vs. PRE values at day 1; Fig. 1C-1E). Interestingly, E-52862 also induced a gradual recovery of the mechanical thresholds measured before its daily administration. This recovery was significant since the seventh day of treatment for all doses tested (Fig. 1C-1E). Hence, the sustained recovery of mechanical thresholds was independent of the E-52862 doses tested.

To evaluate the persistence of E-52862-induced antiallodynic effects, we continued the evaluation of mechanical thresholds after ending the repeated treatment (wash-out period; Fig. 1F-1G). Mice previously treated with vehicle or E-52862 (20 mg/kg, 14 days) were evaluated for 15 additional days after ending the treatment. The reduction of mechanical allodynia induced by the 14-day treatment was maintained for 9 days after interrupting E-52862 administration (Fig. 1G). Therefore, o1R blockade had sustained antiallodynic effects that lasted for several days after treatment discontinuation. 


\subsection{The analgesic efficacy of acute or repeated treatments with E-52862 depends on the stage of}

the osteoarthritis pain sensitization.

$\sigma 1 R$ antagonist treatment showed acute and long-lasting efficacy inhibiting osteoarthritis pain at stages in which inflammatory and neuroplastic changes may have not been fully developed. Thus, we wanted to assess its analgesic efficacy once these changes were already present. We compared the efficacy of acute and chronic E-52862 treatments starting 1 (Early) or 15 (Late) days after MIA injection (Fig. 2A). MIA-injected mice showed similar decrease of mechanical thresholds 1 and 15 days after MIA (Fig. 1B, 2B). We observed a significant shift to the left of the dose-response curve of E-52862 measured 15 days after MIA injection, when compared with the curve assessed on day 1 (Fig. 2C). This was reflected in lower median effective dose $\left(E D_{50}\right)$ of the $\sigma 1 R$ antagonist 15 days after MIA $\left(E D_{50}=\right.$ $7.024 \mathrm{mg} / \mathrm{kg}$ ) than on day $1\left(E D_{50}=14.10 \mathrm{mg} / \mathrm{kg}\right)$. Thus, the dose needed to induce pain relief on day 15 was half of the dose required on day 1.

Comparison between early and late repeated treatments with E-52862 (5 and $10 \mathrm{mg} / \mathrm{kg}$ ) revealed that the time period in which the $\sigma 1 R$ antagonist was applied had a significant effect on the gradual recovery of mechanical thresholds. MIA-induced sensitization was stable in vehicle-treated mice up to 28 days after intra-knee injection (Fig. 2B). Mice receiving the late chronic E-52862 treatment also showed the sustained restoration of mechanical sensitivity observed in the previous treatment schedule (Fig. 2D, 2F), but this improvement was slower compared to the treatment starting at day 1, as reflected on reduced slopes of the time-course curves of mechanical allodynia (Fig. 2E, 2G). Therefore, late repeated treatments with E-52862 required longer time to restore mechanical thresholds than early treatments, even if single administrations at late time points showed higher acute antinociceptive effects.

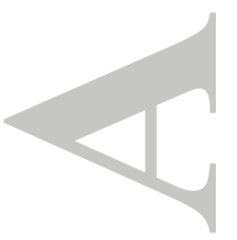




\subsection{Spinal $\sigma 1 R$ antagonist reduces evoked firing frequency of spinal neurons from mice with}

osteoarthritis pain

To distinguish whether E-52862 could modulate central sensitization in the spinal cord of mice with osteoarthritis pain (Harvey and Dickenson, 2009), in vivo electrophysiological recordings were performed in WDR neurons of lamina $\mathrm{V}$ of the dorsal horn. These neurons respond to mechanical and thermal stimuli, including punctate stimulation, dynamic brush, static pressure and heat (Fig. 3A). In this exploratory experiment, evoked responses to punctate mechanical stimuli were facilitated in osteoarthritic mice (Fig. 3B). However, firing frequency evoked by the other stimuli was similar in MIA and sham animals (Fig. 3C). Application of $90 \mu \mathrm{g}$ of E-52862 to the exposed dorsal horn of mice with osteoarthritis significantly reduced firing frequency in response to mechanical and thermal stimuli 30 min after administration (Fig. 3D, 3E). Application of $180 \mu \mathrm{g}$ induced earlier inhibitory effects that were evident 10 and 30 min after E-52862 (Fig. 3F, 3G), indicating dose-dependent drug effects. Hence, MIA induced central sensitization characterized by increased firing frequency of spinal WDR neurons that was normalized by the pharmacological blockade of $\sigma 1 \mathrm{R}$. This effect is associated with the short-term antiallodynic effects of E-52862 observed in mice with osteoarthritis pain.

\section{4. $01 \mathrm{R}$ and MOR show reciprocal modulation in chronic osteoarthritis pain}

$\sigma 1 \mathrm{R}$ has shown a role modulating opioid tolerance during acute nociception (Chien and Pasternak, 1995; Mei and Pasternak, 2002), but this effect has not been investigated under chronic pain conditions. To address this question, we induced opioid tolerance in mice with osteoarthritis pain using a chronic treatment with $2.5 \mathrm{mg} / \mathrm{kg}$ morphine administered twice a day during 14 days. Afterwards, mice received acute morphine $(2.5 \mathrm{mg} / \mathrm{kg}), \mathrm{E}-52862(5-20 \mathrm{mg} / \mathrm{kg})$ or combinations of both and mechanical sensitivity was assessed (Fig. 4A). Osteoarthritic mice developed tolerance to morphine antinociceptive effects, revealed by the absence of opioid response at the end of the repeated treatment (Fig. 4B-4D). This tolerance persisted for at least 9 days, since morphine antinociception was still absent 17, 20 and 23 days after MIA (Fig. 4B). In this context, a single sub- 
effective dose of E-52862 $(5 \mathrm{mg} / \mathrm{kg})$ combined with morphine restored opioid analgesia (days 17 and 23, Fig. 4C). This restorative effect was not observed when morphine was administered alone three days after the first morphine-E-52862 combination, suggesting that may be a transient effect (day 20;

Fig. 4C). To assess the effect of higher doses of the $\sigma 1 R$ antagonist, we co-administered E-52862 20 $\mathrm{mg} / \mathrm{kg}$ with morphine. As expected, this combination produced complete restoration of mechanosensitivity to baseline levels (days 17 and 23, Fig. 4D). Interestingly, this dose induced a longlasting recovery, revealed by increased mechanical thresholds when morphine was given alone three days after the first morphine-E-52862 combination (day 20, Fig. 4D). This was not a residual effect of the former E-52862 dose, since the mechanical sensitivity assessed before the administration of morphine showed regular nociceptive sensitization (Fig. 4D). Therefore, these results suggest that $\sigma 1 \mathrm{R}$ participates in morphine tolerance during chronic osteoarthritis pain and its antagonism can restore opioid analgesia.

The $\sigma 1 R$ antagonist showed efficacy increasing the antinociceptive effect of morphine. However, it is unknown whether MOR contributes to the analgesic effects of $\sigma 1 \mathrm{R}$ ligands. Thus, we evaluated the involvement of $\sigma 1 R$ and MOR on the analgesic efficacy of E-52862. Mice with osteoarthritis pain were treated with vehicle or E-52862 for 13 days and on day 14 received acute doses of E-52862 (20 mg/kg), naloxone (1 mg/kg), the $\sigma 1 R$ agonist PRE-084 (32 mg/kg) or combinations of these drugs (Fig. 5A). MIA-injected mice receiving vehicle showed reduced mechanical thresholds before drug administration (PRE values; Fig. 5B). Acute injection of E-52862 decreased mechanical allodynia, whereas acute naloxone or PRE-084 did not induce significant responses. As expected, PRE-084 reduced the acute antiallodynic effect of the $\sigma 1 \mathrm{R}$ antagonist (Fig. 5B). Interestingly, co-administration of E-52862 with naloxone revealed a trend towards reduced analgesic effects of the $\sigma 1 \mathrm{R}$ antagonist (Fig. 5B), suggesting also MOR contribution to these acute responses. We also investigated whether MOR participates in the sustained recovery of mechanical thresholds induced by repeated E- 52862 (PRE values; Fig. 5C). In these conditions, both naloxone and PRE-084 injections decreased the mechanical thresholds (Fig. 5C). Hence, the results indicate that the effects of E-52862 were selective 
for the $\sigma 1 R$ and a possible participation of MOR on the acute and sustained effects of E-52862 was noted.

An additional experiment was conducted to assess whether chronic stimulation of MOR could in turn modulate E-52862-induced antinociception. Different E-52862 doses were administered to mice with osteoarthritis pain after chronic morphine or vehicle (Fig. 5A, 5D). Interestingly, we observed a significant shift to the right of the E-52862 dose-response curve when the drug was administered to morphine-tolerant mice. The $\sigma 1 \mathrm{R}$ antagonist produced higher antinociceptive effects when mice were not exposed to morphine $\left(E D_{50}=7.028 \mathrm{mg} / \mathrm{kg}\right)$ than when mice were chronically treated with the opioid $\left(E D_{50}=17.77 \mathrm{mg} / \mathrm{kg}\right)$. Thus, the antinociceptive effect of $E-52862$ was 2.5 times lower when MOR was desensitized after repeated morphine. Hence, the results suggest bidirectional modulation of $\sigma 1 R$ and MOR during chronic osteoarthritis pain.

\subsection{Molecular changes associated with chronic osteoarthritis pain are reversed by repeated}

\section{treatment with the $\sigma 1 R$ antagonist E-52862}

The $\sigma 1 R$ antagonist induced acute and long-lasting analgesic effects in mice with osteoarthritis pain, in contrast with morphine, which was void of antinociceptive effects after 14-days repeated administration. To compare the effects of these drugs at the molecular level, expression of markers associated with chronic pain were assessed in DRG and spinal cord samples of sham- or MIA-injected mice treated with vehicle, morphine or E-52862 (Fig. 6). One day after MIA, BDNF and NPY were overexpressed in the DRG (Fig. 6B, 6C). This overexpression was reduced by acute morphine administration, but not by acute E-52862 (Fig. 6B, 6C). This suggests peripheral effects of acute morphine treatments at early time points of the intra-knee injury. At spinal level, MIA-injected mice also showed early over-expression of TNF $\alpha$ (Fig. 6D), whereas IL1 $\beta$ and NPY were unchanged (Fig. 6E, 6F). No effect of the treatments was observed on these spinal markers at this early time point (Fig. 6D-6F). 
After the 14-days treatment with vehicle, BDNF and TNF $\alpha$ kept increased in osteoarthritic mice (Fig. 6B, 6D), whereas NPY levels in the DRG showed massive over-expression (Fig. 6C). At this time point, spinal IL1 $\beta$ and NPY levels were also enhanced (Fig. 6E, 6F). Thus, additional molecular changes were established at later stages of osteoarthritis pain. Continuous $\sigma 1 \mathrm{R}$ blockade normalized the overexpression of all these markers (Fig. 6B-6F), whereas chronic morphine further increased BDNF, IL1ß and spinal NPY expression (Fig. 6B, 6E, 6F). Thus, the $\sigma 1 \mathrm{R}$ antagonist disrupted the expression of pain signalling-related molecules after chronic treatment, whereas repeated morphine promoted the expression of neuroinflammatory mediators.

To further investigate the neuroinflammatory mechanisms underlying the long-term effects of E52862 and morphine, we also analysed protein levels of the macrophage and microglial marker Iba-1 in DRG and spinal cord (Fig. 7A). We did not observe significant differences in DRG (Fig. 7B). In contrast, increased spinal Iba-1 levels were detected in osteoarthritic mice and after repeated morphine (Fig. 7C). Interestingly, E-52862 reversed the enhancement of Iba-1 expression associated with osteoarthritis pain, suggesting a role of $\sigma 1 \mathrm{R}$ modulating glial reactivity. Since microgliosis is associated with glutamate excitotoxicity on neurons (Takeuchi, 2013), we decided to explore the spinal levels of glutamate receptors. We observed that chronic morphine significantly increased the levels of GluR2 AMPA receptor subunit (Fig. 7D), whereas MIA enhanced phosphorylation of the NMDA receptor subunits NR1 and NR2B and the expression of metabotropic glutamate receptor mGluR5 (Fig. 7E-7G). While the increases in phospho-NR1 and phospho-NR2B were independent of the treatment, the results showed that mGluR5 over-expression was completely reversed by E-52862 (Fig. 7G), revealing a novel effect of $\sigma 1 R$ antagonism modulating glutamatergic signalling.

Hence, morphine showed acute effects diminishing expression of peripheral nociceptive markers, but chronic administration aggravated the pain-related molecular changes. On the contrary, E-52862 did not affect the expression of these markers after acute administration, but the repeated treatment abolished central and peripheral long-term alterations associated with chronic osteoarthritis pain. 


\section{Discussion}

This work reveals that the selective $\sigma 1 \mathrm{R}$ antagonist E-52862 has short and long-term analgesic effects and reverses morphine tolerance in mice subjected to a model of chronic osteoarthritis pain. Our findings indicate dose-dependent short-term antinociception observed 30 min after E-52862 and sustained recovery of the mechanical thresholds when the drug is repeatedly given. Importantly, electrophysiological recordings revealed that E-52862 inhibited central sensitization of spinal WDR neurons in osteoarthritic mice. These effects partially involved MOR, and $\sigma 1 \mathrm{R}$ antagonism reversed morphine tolerance during osteoarthritis pain, evidencing a crosstalk between $\sigma 1 \mathrm{R}$ and the opioid system. Biochemical assays identify common alterations of neuroinflammatory markers and glutamatergic signalling associated with chronic pain and repeated opioid exposure, both specifically inhibited by E-52862.

Acute E-52862 induced short-term inhibition of MIA-induced hypersensitivity, confirming the analgesic efficacy of the $\sigma 1 \mathrm{R}$ antagonist observed in different pain models (Romero et al., 2016). E52862 or vehicle treatments did not induce significant changes in mechanical sensitivity of sham mice, although minor variations associated with the intra-knee saline injections were occasionally observed. Thus, normal mechanosensitivity remains intact following $\sigma 1 \mathrm{R}$ antagonism. In agreement, it was proposed that $\sigma 1 \mathrm{R}$ do not have a primary role in physiological conditions (Su et al., 2010; Zamanillo et al., 2013). The repeated treatment with E-52862 also promoted a gradual recovery of sensitivity, which was observed with all the doses tested and maintained after interrupting the treatment. Previous studies in mice investigated acute E-52862 antinociceptive effects (Romero et al., 2012; González-Cano et al., 2013; Gris et al., 2014) and its effects during chronic administration without testing mechanical allodynia before the daily dose of the compound (Romero et al., 2012; Bura et al., 2013). Our work shows long-lasting restorative effects of the $\sigma 1 \mathrm{R}$ antagonist, suggesting an additional benefit for long-term chronic pain treatments.

This article is protected by copyright. All rights reserved. 
E-52862 showed different efficacy depending on the stage of the osteoarthritis pain sensitization. It was proposed that the initial mechanical hyperalgesia in osteoarthritis is caused by inflammatory processes, while later stages involve neuropathic mechanisms (Thakur et al., 2012). In agreement, rat models showed increase of nerve injury marker ATF- 3 in the DRG between 8 and 14 days after MIA (Ivanavicius et al., 2007; Orita et al., 2011), and our mice increased expression of neuroinflammatory markers 15 days after intra-knee injury. The E-52862 doses needed to exert acute antiallodynic effect 15 days after MIA were lower than 1 day post-injection. Thus, acute effects of E-52862 were more prominent once the neuropathic component of osteoarthritis was established. Such intra-model differences agree with previous results showing higher E-52862 efficacy after neuropathic injuries than during inflammatory pain (Romero et al., 2012; Gris et al., 2014). The long-lasting alleviation of pain required longer exposure to the $\sigma 1 \mathrm{R}$ antagonist when persistent neuroinflammatory changes were present, although E-52862 was still able to restore normal sensitivity. Thus, the $\sigma 1 \mathrm{R}$ antagonist showed higher short-term analgesic efficacy when pain chronification develops while preserving its long-term effects on chronic pain sensitization.

In vivo electrophysiological recordings showed facilitation of the firing frequency of spinal WDR neurons after MIA, revealing central sensitization in mice with osteoarthritis pain. Our result in CD1 mice agrees with previous work using $\mathrm{C} 57 \mathrm{BI} / 6$ mice, which revealed similar MIA-induced responses to mechanical stimuli (Harvey and Dickenson, 2009). Furthermore, the lack of increased firing in response to thermal stimuli is in agreement with previous behavioural studies showing that MIA-injected mice do not exhibit consistent heat hyperalgesia (La Porta et al., 2013). Interestingly, we found that intrathecal application of E-52862 reduced these MIA-facilitated responses. This is in line with previous ex vivo electrophysiological studies showing that E-52862 inhibited wind-up responses elicited after repeated nociceptor stimulation (Romero et al., 2012). In agreement, spinal cords of $\sigma 1 \mathrm{R}$ knockout mice exhibited reduced wind-up responses compared to wild-type mice (de la Puente et al., 2009). Therefore, our experiments demonstrate that spinal central sensitization associated to osteoarthritis pain in live animals is reversed by the $\sigma 1 \mathrm{R}$ antagonist.

This article is protected by copyright. All rights reserved. 
It was postulated that $\sigma 1 \mathrm{R}$ promotes MOR phosphorylation, a process involved in opioid tolerance (Rodríguez-Muñoz et al., 2015a, 2015b). We revealed $\sigma 1$ R-modulation of opioid analgesia during chronic osteoarthritis pain, showing that a single sub-effective dose of E-52862 co-administered with morphine restored opioid antinociception. Previous preclinical research evidenced this modulatory role in the absence of chronic pain using $\sigma 1 \mathrm{R}$ knockout mice and $\sigma 1 \mathrm{R}$ antagonists (Chien and Pasternak, 1994; Sánchez-Fernández et al., 2013, 2014). Moreover, E-52862 demonstrated efficacy restoring morphine analgesia in tolerant animals with acute nociceptive and inflammatory pain (Vidal-Torres et al., 2013; Rodríguez-Muñoz et al., 2015b; Montilla-García et al., 2019). Surprisingly there were no previous studies assessing the role of $\sigma 1 \mathrm{R}$ modulating opioid analgesia under chronic painful conditions. Our data suggest that $\sigma 1 \mathrm{R}$ antagonists could be efficient not only alleviating pain by themselves, but also restoring opioid analgesia in tolerant individuals. Taking into account that opioid tolerance drives dose escalation and abuse, and E-52862 did not produce tolerance development during this long-term treatment and it is void of reinforcing effects in animals without pain (Bura et al., 2013), the $\sigma 1 R$ antagonist could represent a valid alternative for chronic pain treatment. Considering the lifespan of mice ( 2.5 years) and humans ( 80 years), the length of the treatment used in this study could be compared to the duration of chronic pain treatments that produce adverse events in patients.

We observed inhibition of E-52862 acute and sustained effects after administration of $\sigma 1 \mathrm{R}$ agonist PRE-084. Previous studies using pharmacological and genetic approaches demonstrated that acute analgesic effects of E-52862 are selectively mediated by $\sigma 1 R$ (Gris et al., 2014; Sánchez-Fernández et al., 2014). Our work also showed that long-term restoration of mechanical thresholds is also $\sigma 1 \mathrm{R}$ dependent. Interestingly, naloxone also diminished the acute and sustained antinociceptive effects of E-52862 revealing opioid participation. In addition, morphine-tolerant mice showed decreased E52862 efficacy. $\sigma 1 R$ antagonism facilitates $\sigma 1 R-M O R$ binding and protects MOR from phosphorylation, hence promoting its activity. Such phosphorylation is enhanced after persistent MOR stimulation (Rodríguez-Muñoz et al., 2015a, 2015b). Since both naloxone and MOR desensitization after chronic 
morphine decreased E-52862 antinociceptive effects, it can be concluded that part of the analgesic effects of the $\sigma 1 \mathrm{R}$ antagonist rely on the enhancement of endogenous MOR activity.

We investigated pain-related molecular alterations involved in morphine and E-52862 analgesia during osteoarthritis. One day after MIA, BDNF and NPY over-expression was observed in the DRG and TNF $\alpha$ expression increased in the spinal cord. Previous studies reported similar changes after nerve injuries, including immediate increases in BDNF and TNF $\alpha$ expression that persisted for long-term periods (Ohtori et al., 2004; Uchida et al., 2013). Several researchers also showed prominent NPY upregulation in nerve-injured primary afferents (Benoliel et al., 2001; Son et al., 2007). This synthesis de novo could represent an adaptive response to nociceptive sensitization (Munglani et al., 1995). While acute morphine inhibited pain-related over-expression of BDNF and NPY, a single E-52862 administration did not provoke such effects, suggesting that its acute effects do not rely on these molecules.

Later stages of osteoarthritis pain involved pronounced increases of IL1 $\beta$ and NPY levels in spinal cord or DRG, accompanied by enhancement of microglial marker Iba1. In addition, the enhanced levels of BDNF and TNF $\alpha$ were maintained in DRG and spinal cord, respectively. Thus, the intra-knee injury induced persistent changes in neuroinflammatory mediators possibly contributing to the osteoarthritic phenotype. These pain-related changes were reported to increase glutamate release and stimulate the glutamatergic system (Takeuchi, 2013; Vaz et al., 2015). In agreement, osteoarthritic mice showed mGluR5 over-expression, which is associated with increased glutamate levels in the nervous system (Wang et al., 2012). As previously described, chronic morphine further increased neuroinflammation and glutamatergic signalling (Johnston et al., 2004; Cabañero et al., 2013), characterized by exacerbated BDNF, IL1 3 , spinal microgliosis and AMPA receptor expression. Interestingly, increased BDNF/TrkB signalling contributes to chronic pain by eliciting microglial reactivity and glutamate release (Zhou et al., 2011). At the same time, IL1 $\beta$ and TNF $\alpha$ are mainly released by activated microglia, which also liberates BDNF after chronic morphine (Takayama and 
Ueda, 2005). Thus, repeated morphine contributed to an overall increase of spinal neuroinflammation. In sharp contrast, chronic E-52862 normalized the expression of BDNF and proinflammatory cytokines. These findings agree with previous studies revealing potentiation of BDNF effects after $\sigma 1 \mathrm{R}$ over-expression (Yagasaki et al., 2006) or chronic $\sigma 1 \mathrm{R}$ activation (Kikuchi-Utsumi and Nakaki, 2008). Likewise, recent experiments showed normalization of TNF $\alpha$ and IL1 $\beta$ expression in spinal cord-injured $\sigma 1 \mathrm{R}$ knockout mice (Castany et al., 2018). E-52862 also reduced MIA-induced microgliosis, consistent with the effects of $\sigma 1 \mathrm{R}$ antagonist BD1047 attenuating spinal microgliosis in a model of bone cancer pain (Zhu et al., 2015) and with the high levels of $\sigma 1 \mathrm{R}$ reported in microglia (Gekker et al., 2006). Interestingly, E-52862 was effective in preventing the increased microglial density induced by MIA in supraspinal structures (Carcolé et al., 2019). In addition, mGluR5 overexpression was completely abolished by E-52862. Hence, contrary to chronic morphine, repeated treatment with the $\sigma 1 \mathrm{R}$ antagonist normalized the expression of neuroinflammatory mediators and glutamate receptors involved in chronic osteoarthritis pain.

The present study shows a dual effect of the $\sigma 1 \mathrm{R}$ antagonist E-52862 alleviating osteoarthritis pain. On the one hand it reduces acute mechanical allodynia, involving inhibition of spinal sensitization without modification of pain-related molecular alterations. On the other hand, repeated E-52862 exposure promotes gradual recovery of the mechanical thresholds in osteoarthritic mice without inducing tolerance. This effect is associated with inhibition of biochemical changes related to osteoarthritis pain and opioid tolerance. Such alterations involve neuroinflammatory mediators, microglial reactivity and glutamatergic signalling, which could constitute a common pathway by which the $\sigma 1 R$ antagonist provides relief of chronic pain and restoration of opioid analgesia in tolerant individuals. Hence, the $\sigma 1 \mathrm{R}$ antagonist could dampen deleterious side effects of opioid prescription drugs, which has reached now dramatic consequences in USA (Lyden and Binswanger, 2019), and represents a promising alternative to opioids in chronic pain conditions requiring long-term treatment. 


\section{Conflict of interest}

The authors state that there were no conflicts of interest in respect to the work reported in this paper.

\section{Declaration of transparency and scientific rigour}

This Declaration acknowledges that this paper adheres to the principles for transparent reporting and scientific rigour of preclinical research as stated in the BJP guidelines for Design \& Analysis, Immunoblotting and Immunochemistry, and Animal Experimentation, and as recommended by funding agencies, publishers and other organisations engaged with supporting research.

\section{References}

Alexander, S.P., Christopoulos, A., Davenport, A.P., Kelly, E., Marrion, N. V, Peters, J.A., et al. (2017a). THE CONCISE GUIDE TO PHARMACOLOGY 2017/18: G protein-coupled receptors. Br. J. Pharmacol. 174: $\$ 17-\$ 129$

Alexander, S.P., Kelly, E., Marrion, N. V, Peters, J.A., Faccenda, E., Harding, S.D., et al. (2017b). THE CONCISE GUIDE TO PHARMACOLOGY 2017/18: Overview. Br. J. Pharmacol. 174: S1-S16.

Alexander, S.P.H., Roberts, R.E., Broughton, B.R.S., Sobey, C.G., George, C.H., Stanford, S.C., et al. (2018). Goals and practicalities of immunoblotting and immunohistochemistry: A guide for submission to the British Journal of Pharmacology. Br. J. Pharmacol. 175: 407-411.

Alonso, G., Phan, V., Guillemain, I., Saunier, M., Legrand, A., Anoal, M., et al. (2000). Immunocytochemical localization of the sigma(1) receptor in the adult rat central nervous system. Neuroscience 97: 155-70. 
Arendt-Nielsen, L., Nie, H., Laursen, M.B., Laursen, B.S., Madeleine, P., Simonsen, O.H., et al. (2010). Sensitization in patients with painful knee osteoarthritis. Pain 149: 573-581.

Bangaru, M.L., Weihrauch, D., Tang, Q.-B., Zoga, V., Hogan, Q., and Wu, H. (2013). Sigma-1 receptor expression in sensory neurons and the effect of painful peripheral nerve injury. Mol. Pain 9: 47.

Benoliel, R., Eliav, E., and ladarola, M.J. (2001). Neuropeptide $Y$ in trigeminal ganglion following chronic constriction injury of the rat infraorbital nerve: is there correlation to somatosensory parameters? Pain 91: 111-21.

Breivik, H., Collett, B., Ventafridda, V., Cohen, R., and Gallacher, D. (2006). Survey of chronic pain in Europe: Prevalence, impact on daily life, and treatment. Eur. J. Pain 10: 287-287.

Bura, A.S., Guegan, T., Zamanillo, D., Vela, J.M., and Maldonado, R. (2013). Operant selfadministration of a sigma ligand improves nociceptive and emotional manifestations of neuropathic pain. Eur. J. Pain 17: 832-843.

Cabañero, D., Baker, A., Zhou, S., Hargett, G.L., Irie, T., Xia, Y., et al. (2013). Pain after discontinuation of morphine treatment is associated with synaptic increase of GluA4-containing AMPAR in the dorsal horn of the spinal cord. Neuropsychopharmacology 38: 1472-84.

Carcolé, M., Zamanillo, D., Merlos, M., Fernández-Pastor, B., Cabañero, D., and Maldonado, R. (2019). Blockade of the Sigma-1 Receptor Relieves Cognitive and Emotional Impairments Associated to Chronic Osteoarthritis Pain. Front. Pharmacol. 10:.

Castany, S., Gris, G., Vela, J.M., Verdú, E., and Boadas-Vaello, P. (2018). Critical role of sigma-1 receptors in central neuropathic pain-related behaviours after mild spinal cord injury in mice. Sci. Rep. 8: 3873.

Chaplan, S.R., Bach, F.W., Pogrel, J.W., Chung, J.M., and Yaksh, T.L. (1994). Quantitative assessment of tactile allodynia in the rat paw. J. Neurosci. Methods 53: 55-63. 
Chien, C.C., and Pasternak, G.W. (1994). Selective antagonism of opioid analgesia by sigma system. J Pharmacol Exp Ther. 271: 1583-1590.

Chien, C.C., and Pasternak, G.W. (1995). Sigma antagonists potentiate opioid analgesia in rats.

Neurosci. Lett. 190:

Curtis, M.J., Alexander, S., Cirino, G., Docherty, J.R., George, C.H., Giembycz, M.A., et al. (2018).

Experimental design and analysis and their reporting II: updated and simplified guidance for authors and peer reviewers. Br. J. Pharmacol. 175: 987-993.

Dixon, W.J. (1965). The Up-and-Down Method for Small Samples. J. Am. Stat. Assoc. 60: 967-978.

Gekker, G., Hu, S., Sheng, W.S., Rock, R.B., Lokensgard, J.R., and Peterson, P.K. (2006). Cocaineinduced HIV-1 expression in microglia involves sigma-1 receptors and transforming growth factorbeta1. Int. Immunopharmacol. 6: 1029-33.

González-Cano, R., Merlos, M., Baeyens, J.M., and Cendán, C.M. (2013). o1 Receptors Are Involved in the Visceral Pain Induced by Intracolonic Administration of Capsaicin in Mice. Anesthesiology 118: $691-700$.

Gris, G., Merlos, M., Vela, J.M., Zamanillo, D., and Portillo-Salido, E. (2014). S1RA, a selective sigma-1 receptor antagonist, inhibits inflammatory pain in the carrageenan and complete Freund's adjuvant models in mice. Behav. Pharmacol. 25: 226-35.

Harding, S.D., Sharman, J.L., Faccenda, E., Southan, C., Pawson, A.J., Ireland, S., et al. (2018). The IUPHAR/BPS Guide to PHARMACOLOGY in 2018: updates and expansion to encompass the new guide to IMMUNOPHARMACOLOGY. Nucleic Acids Res. 46: D1091-D1106.

Harvey, V.L., and Dickenson, A.H. (2009). Behavioural and electrophysiological characterisation of experimentally induced osteoarthritis and neuropathy in C57BI/6 mice. Mol. Pain 5: 18.

Hayashi, T., and Su, T.-P. (2007). Sigma-1 receptor chaperones at the ER-mitochondrion interface 
regulate $\mathrm{Ca}(2+)$ signaling and cell survival. Cell 131: 596-610.

Inceoglu, B., Bettaieb, A., Trindade da Silva, C.A., Lee, K.S.S., Haj, F.G., and Hammock, B.D. (2015). Endoplasmic reticulum stress in the peripheral nervous system is a significant driver of neuropathic pain. Proc. Natl. Acad. Sci. 112: 9082-9087.

Ivanavicius, S.P., Ball, A.D., Heapy, C.G., Westwood, F.R., Murray, F., and Read, S.J. (2007). Structural pathology in a rodent model of osteoarthritis is associated with neuropathic pain: increased expression of ATF-3 and pharmacological characterisation. Pain 128: 272-82.

Johnston, I.N., Milligan, E.D., Wieseler-Frank, J., Frank, M.G., Zapata, V., Campisi, J., et al. (2004). A Role for Proinflammatory Cytokines and Fractalkine in Analgesia, Tolerance, and Subsequent Pain Facilitation Induced by Chronic Intrathecal Morphine. J. Neurosci. 24: 7353-7365.

Kikuchi-Utsumi, K., and Nakaki, T. (2008). Chronic treatment with a selective ligand for the sigma-1 receptor chaperone, SA4503, up-regulates BDNF protein levels in the rat hippocampus. Neurosci. Lett. 440: 19-22.

Kim, F.J., Kovalyshyn, I., Burgman, M., Neilan, C., Chien, C.-C., and Pasternak, G.W. (2010). Sigma-1 Receptor Modulation of G-Protein-Coupled Receptor Signaling: Potentiation of Opioid Transduction Independent from Receptor Binding. Mol. Pharmacol. 77: 695-703.

la Puente, B. de, Nadal, X., Portillo-Salido, E., Sánchez-Arroyos, R., Ovalle, S., Palacios, G., et al. (2009). Sigma-1 receptors regulate activity-induced spinal sensitization and neuropathic pain after peripheral nerve injury. Pain 145: 294-303.

Liu, D., Zhou, Y., Peng, Y., Su, P., Li, Z., Xu, Q., et al. (2018). Endoplasmic Reticulum Stress in Spinal Cord Contributes to the Development of Morphine Tolerance. Front. Mol. Neurosci. 11: 72.

Livak, K.J., and Schmittgen, T.D. (2001). Analysis of Relative Gene Expression Data Using Real-Time Quantitative PCR and the 2- $\Delta \Delta C T$ Method. Methods 25: 402-408.

This article is protected by copyright. All rights reserved. 
Lyden, J., and Binswanger, I.A. (2019). The United States opioid epidemic. Semin. Perinatol. 43: 123131.

Mei, J., and Pasternak, G.W. (2002). Sigma1 receptor modulation of opioid analgesia in the mouse. J. Pharmacol. Exp. Ther. 300: 1070-1074.

Montilla-García, Á., Tejada, M.Á., Ruiz-Cantero, M.C., Bravo-Caparrós, I., Yeste, S., Zamanillo, D., et al. (2019). Modulation by Sigma-1 Receptor of Morphine Analgesia and Tolerance: Nociceptive Pain, Tactile Allodynia and Grip Strength Deficits During Joint Inflammation. Front. Pharmacol. 10: 136.

Munglani, R., Bond, A., Smith, G.D., Harrison, S.M., Elliot, P.J., Birch, P.J., et al. (1995). Changes in neuronal markers in a mononeuropathic rat model relationship between neuropeptide $Y$, preemptive drug treatment and long-term mechanical hyperalgesia. Pain 63: 21-31.

Negrete, R., García Gutiérrez, M.S., Manzanares, J., and Maldonado, R. (2017). Involvement of the dynorphin/KOR system on the nociceptive, emotional and cognitive manifestations of joint pain in mice. Neuropharmacology 116: 315-327.

Ohtori, S., Takahashi, K., Moriya, H., and Myers, R.R. (2004). TNF-alpha and TNF-alpha receptor type 1 upregulation in glia and neurons after peripheral nerve injury: studies in murine DRG and spinal cord. Spine (Phila. Pa. 1976). 29: 1082-8.

Orita, S., Ishikawa, T., Miyagi, M., Ochiai, N., Inoue, G., Eguchi, Y., et al. (2011). Pain-related sensory innervation in monoiodoacetate-induced osteoarthritis in rat knees that gradually develops neuronal injury in addition to inflammatory pain. BMC Musculoskelet. Disord. 12: 134.

Ozaita, A., Puighermanal, E., and Maldonado, R. (2007). Regulation of PI3K/Akt/GSK-3 pathway by cannabinoids in the brain. J. Neurochem. 102: 1105-1114.

Porta, C. La, Bura, S.A., Aracil-Fernández, A., Manzanares, J., and Maldonado, R. (2013). Role of CB1 and CB2 cannabinoid receptors in the development of joint pain induced by monosodium 
iodoacetate. Pain 154: 160-174.

Rodríguez-Muñoz, M., Cortés-Montero, E., Pozo-Rodrigálvarez, A., Sánchez-Blázquez, P., and GarzónNiño, J. (2015a). The ON:OFF switch, o1R-HINT1 protein, controls GPCR-NMDA receptor crossregulation: implications in neurological disorders. Oncotarget 6: 35458-77.

Rodríguez-Muñoz, M., Sánchez-Blázquez, P., Herrero-Labrador, R., Martínez-Murillo, R., Merlos, M., Vela, J.M., et al. (2015b). The $\sigma 1$ receptor engages the redox-regulated HINT1 protein to bring opioid analgesia under NMDA receptor negative control. Antioxid. Redox Signal. 22: 799-818.

Romero, L., Merlos, M., and Vela, J.M. (2016). Antinociception by Sigma-1 Receptor Antagonists: Central and Peripheral Effects. In Advances in Pharmacology (San Diego, Calif.), pp 179-215.

Romero, L., Zamanillo, D., Nadal, X., Sánchez-Arroyos, R., Rivera-Arconada, I., Dordal, a., et al. (2012). Pharmacological properties of S1RA, a new sigma-1 receptor antagonist that inhibits neuropathic pain and activity-induced spinal sensitization. Br. J. Pharmacol. 166: 2289-2306.

Sánchez-Fernández, C., Montilla-Garcia, A., Gonzalez-Cano, R., Nieto, F.R., Romero, L., ArtachoCordon, A., et al. (2014). Modulation of Peripheral mu-Opioid Analgesia by 1 Receptors. J. Pharmacol. Exp. Ther. 348: 32-45.

Sánchez-Fernández, C., Nieto, F.R., González-Cano, R., Artacho-Cordón, A., Romero, L., MontillaGarcía, Á., et al. (2013). Potentiation of morphine-induced mechanical antinociception by $\sigma 1$ receptor inhibition: Role of peripheral $\sigma 1$ receptors. Neuropharmacology 70: 348-358.

Son, S.-J., Lee, K.-M., Jeon, S.-M., Park, E.-S., Park, K.-M., and Cho, H.-J. (2007). Activation of transcription factor c-jun in dorsal root ganglia induces VIP and NPY upregulation and contributes to the pathogenesis of neuropathic pain. Exp. Neurol. 204: 467-472.

Su, T.-P., Hayashi, T., Maurice, T., Buch, S., and Ruoho, A.E. (2010). The sigma-1 receptor chaperone as an inter-organelle signaling modulator. Trends Pharmacol. Sci. 31: 557-566. 
Sutton, S., Clutterbuck, A., Harris, P., Gent, T., Freeman, S., Foster, N., et al. (2009). The contribution of the synovium, synovial derived inflammatory cytokines and neuropeptides to the pathogenesis of osteoarthritis. Vet. J. 179: 10-24.

Takayama, N., and Ueda, H. (2005). Morphine-Induced Chemotaxis and Brain-Derived Neurotrophic Factor Expression in Microglia. J. Neurosci. 25: 430-435.

Takeuchi, H. (2013). Microglia and glutamate. In Advances in Neuroimmune Biology, pp 77-83.

Thakur, M., Rahman, W., Hobbs, C., Dickenson, A.H., and Bennett, D.L.H. (2012). Characterisation of a peripheral neuropathic component of the rat monoiodoacetate model of osteoarthritis. PLoS One 7: e33730.

Uchida, H., Matsushita, Y., and Ueda, H. (2013). Epigenetic regulation of BDNF expression in the primary sensory neurons after peripheral nerve injury: Implications in the development of neuropathic pain. Neuroscience 240: 147-154.

Vaz, S.H., Lérias, S.R., Parreira, S., Diógenes, M.J., and Sebastião, A.M. (2015). Adenosine A2A receptor activation is determinant for BDNF actions upon GABA and glutamate release from rat hippocampal synaptosomes. Purinergic Signal. 11: 607-612.

Vidal-Torres, A., Fernández-Pastor, B., Carceller, A., Vela, J.M., Merlos, M., and Zamanillo, D. (2014). Effects of the selective sigma-1 receptor antagonist S1RA on formalin-induced pain behavior and neurotransmitter release in the spinal cord in rats. J. Neurochem. 129: 484-494.

Vidal-Torres, A., la Puente, B. de, Rocasalbas, M., Touriño, C., Bura, S.A., Fernández-Pastor, B., et al. (2013). Sigma-1 receptor antagonism as opioid adjuvant strategy: enhancement of opioid antinociception without increasing adverse effects. Eur. J. Pharmacol. 711: 63-72.

Vowles, K.E., McEntee, M.L., Julnes, P.S., Frohe, T., Ney, J.P., and Goes, D.N. van der (2015). Rates of opioid misuse, abuse, and addiction in chronic pain: a systematic review and data synthesis. Pain 
156: 569-76.

Wang, J.-W., Wang, H.-D., Zhong, W.-Z., Li, N., and Cong, Z.-X. (2012). Expression and cell distribution of metabotropic glutamate receptor 5 in the rat cortex following traumatic brain injury. Brain Res.

1464: 73-81.

Wieland, H.A., Michaelis, M., Kirschbaum, B.J., and Rudolphi, K.A. (2005). Osteoarthritis - an untreatable disease? Nat. Rev. Drug Discov. 4: 331-344.

Wylde, V., Hewlett, S., Learmonth, I.D., and Dieppe, P. (2011). Persistent pain after joint replacement: Prevalence, sensory qualities, and postoperative determinants. Pain 152: 566-572.

Yagasaki, Y., Numakawa, T., Kumamaru, E., Hayashi, T., Su, T.-P., and Kunugi, H. (2006). Chronic antidepressants potentiate via sigma-1 receptors the brain-derived neurotrophic factor-induced signaling for glutamate release. J. Biol. Chem. 281: 12941-9.

Zamanillo, D., Romero, L., Merlos, M., and Vela, J.M. (2013). Sigma 1 receptor: A new therapeutic target for pain. Eur. J. Pharmacol. 716: 78-93.

Zhang, R.-X., Ren, K., and Dubner, R. (2013). Osteoarthritis pain mechanisms: basic studies in animal models. Osteoarthr. Cartil. 21: 1308-1315.

Zhou, L.-J., Yang, T., Wei, X., Liu, Y., Xin, W.-J., Chen, Y., et al. (2011). Brain-derived neurotrophic factor contributes to spinal long-term potentiation and mechanical hypersensitivity by activation of spinal microglia in rat. Brain. Behav. Immun. 25: 322-334.

Zhu, S., Wang, C., Han, Y., Song, C., Hu, X., and Liu, Y. (2015). Sigma-1 Receptor Antagonist BD1047 Reduces Mechanical Allodynia in a Rat Model of Bone Cancer Pain through the Inhibition of Spinal NR1 Phosphorylation and Microglia Activation. Mediators Inflamm. 2015: 1-11.

Zimmermann, M. (1986). Ethical considerations in relation to pain in animal experimentation. Acta Physiol. Scand. Suppl. 554: 221-33. 


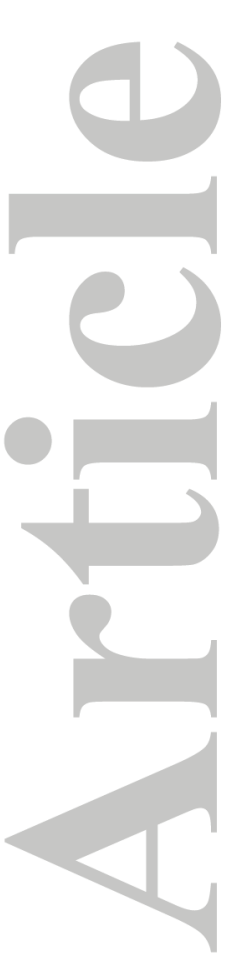

A Sham
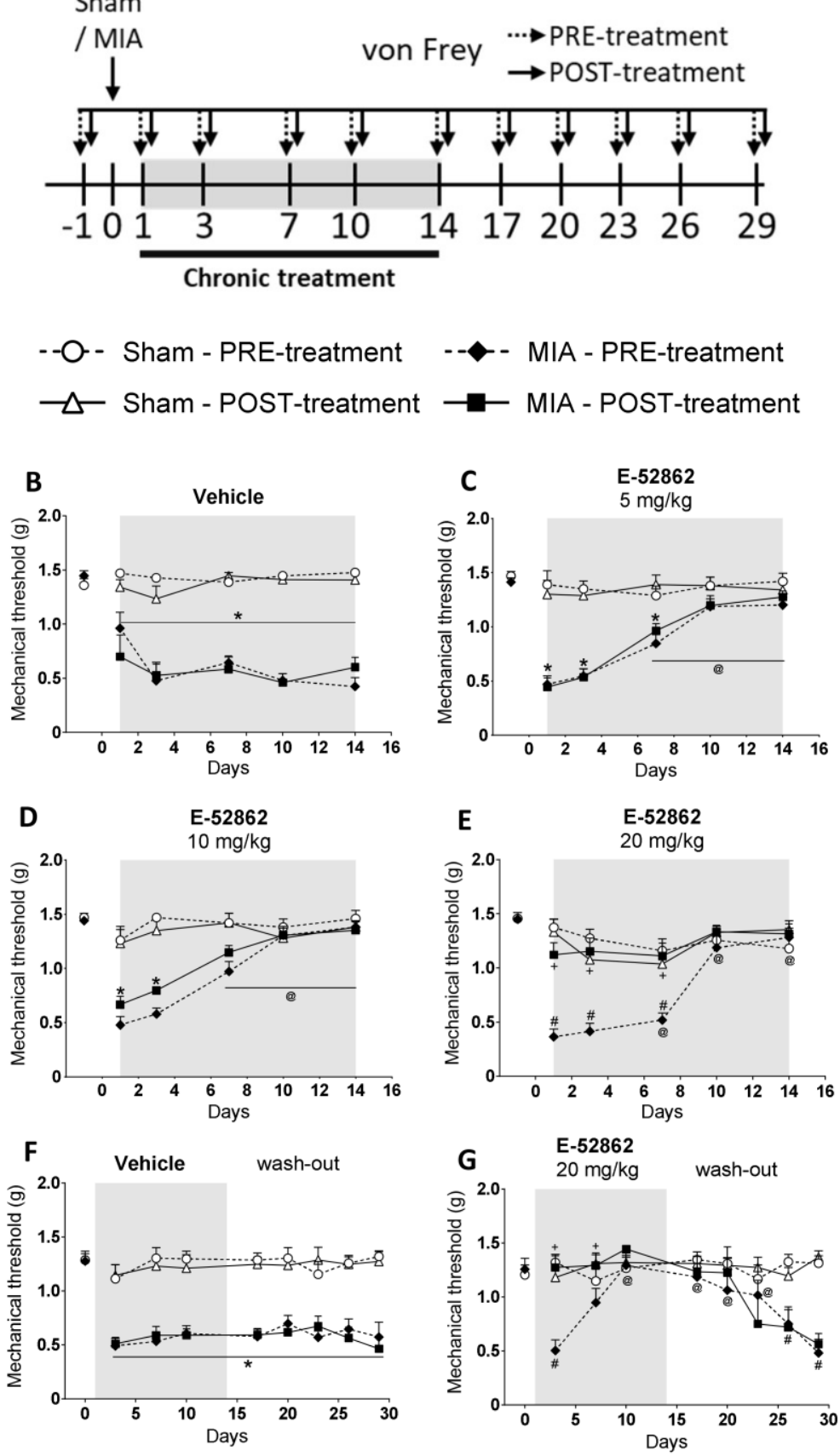

Figure 1. O1R antagonist E-52862 produces both acute anti-allodynia and a gradual normalization of mechanical thresholds during osteoarthritis pain. (A) Mice received an intra-knee injection of MIA or saline and were treated with vehicle $(0.5 \% \mathrm{HMPC})$ or $\mathrm{E}-52862(5,10$ or $20 \mathrm{mg} / \mathrm{kg})$ twice a day from day 1 to day 14. Mechanical allodynia was assessed with the von Frey test before (PRE) and 30 min after (POST) the first daily dose, under basal conditions and 1, 3, 7, 10, 14, and 17, 20, 23, 26 and 29 
days after the intra-articular injection. (B) MIA-injected mice treated with vehicle showed a persistent decrease on mechanical thresholds. (C, D, E) E-52862 produced acute dose-dependent antiallodynic effects (POST values) and a gradual recovery of mechanical thresholds observed before the daily doses (PRE values). (F) MIA-induced reduction of mechanical thresholds persisted up to 29 days in vehicletreated mice. (G) The sustained recovery induced by chronic E-52862 was maintained for 9 days after interrupting the repeated treatment. The von Frey pressure $(\mathrm{g})$ required to elicit the paw withdrawal is expressed as mean \pm SEM. The number of animals is (first value represents sham groups and second value represents MIA groups): (B) 8, 8; (C) 8, 8; (D) 8, 8; (E) 8, 10; (F) 8, 16; (G) 8, 8. * for MIA vs. Sham; @ for MIA-PRE vs. MIA-PRE at day 1; \# for MIA-PRE vs. Sham-PRE; + for MIA-PRE vs. MIA-POST (3-way repeated measures ANOVA plus Fisher least significant difference test). MIA, monoiodoacetate; SEM, standard error of the mean.

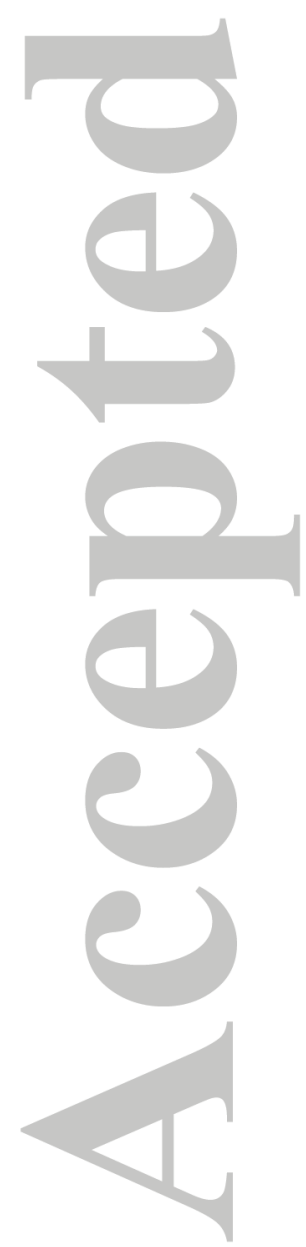


A
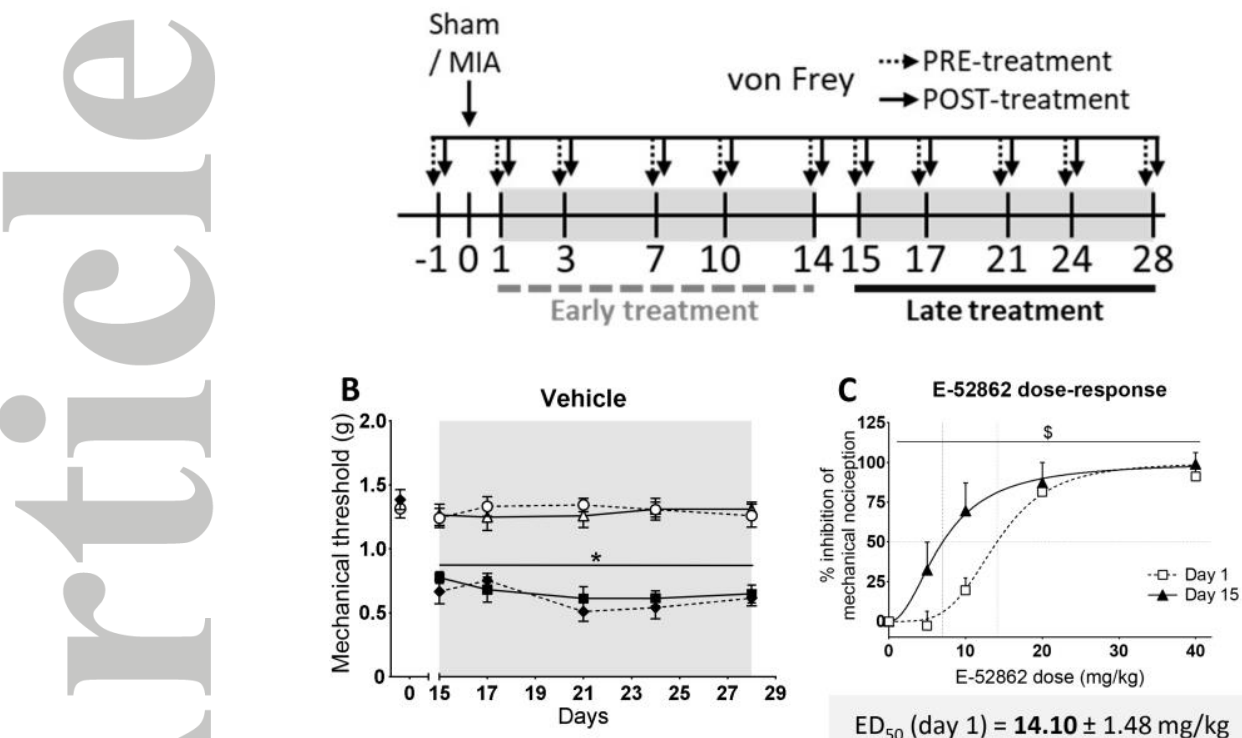

$\mathrm{ED}_{50}($ day 1$)=\mathbf{1 4 . 1 0} \pm 1.48 \mathrm{mg} / \mathrm{kg}$ $\mathrm{ED}_{50}($ day 15$)=\mathbf{7 . 0 2} \pm 1.45 \mathrm{mg} / \mathrm{kg}$
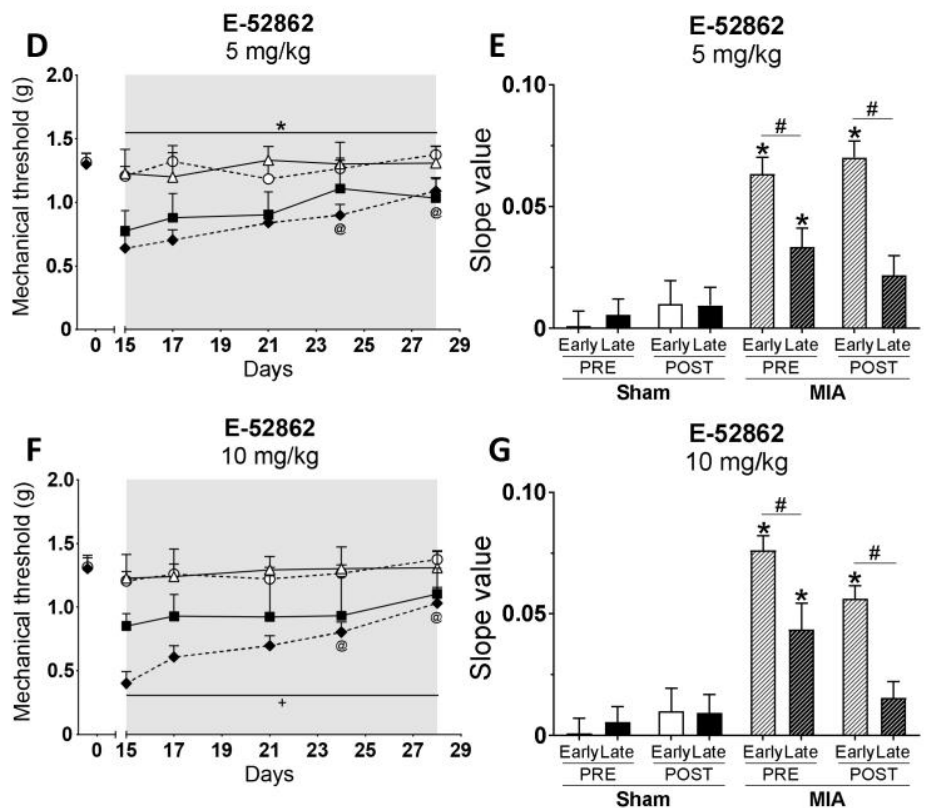

--O- Sham - PRE-treatment

-- - MIA - PRE-treatment

$\checkmark-$ Sham - POST-treatment

$\rightarrow-$ MIA - POST-treatment

Figure 2. Acute and repeated E-52862 treatments starting 1 or 15 days after MIA injection differ in their analgesic efficacy. (A) The analgesic effects of acute and chronic E-52862 (5 or $10 \mathrm{mg} / \mathrm{kg}$, twice a day during 14 days) were compared between treatments starting 1 (Early) or 15 (Late) days after the injection of MIA. (B) MIA-induced sensitization was stable in vehicle-treated mice from day 15 to 28 
after intra-knee injection. (C) Lower doses were needed to induce acute relief of mechanical hypersensitivity 15 than 1 days after the intra-knee injection of MIA. Mice receiving chronic late treatments with E-52862 $5 \mathrm{mg} / \mathrm{kg}$ (D) and $10 \mathrm{mg} / \mathrm{kg}$ (F) also showed a recovery of the mechanical thresholds. (E, G) The restoration of mechanical sensitivity was slower in the late than in the early treatment protocol, as reflected on reduced slopes of the time-course curves of mechanical allodynia. Data are expressed as mean \pm SEM. The number of animals is (first value represents day 1 or sham groups and second value represents day 15 or MIA groups): (B) 9, 8; (C) 10, 8; (D) 8, 8; (F) 8, 8. For panels B, D, E, F, G: * for MIA vs. Sham; @ for MIA vs. MIA at day 1; + for MIA-PRE vs. MIA-POST (3way repeated measures ANOVA plus Fisher least significant difference test). For panel C: $\$$ for day 1 vs. day 15 (F-test of non-linear regression). ED 50 , median effective dose; MIA, monoiodoacetate; SEM, standard error of the mean.

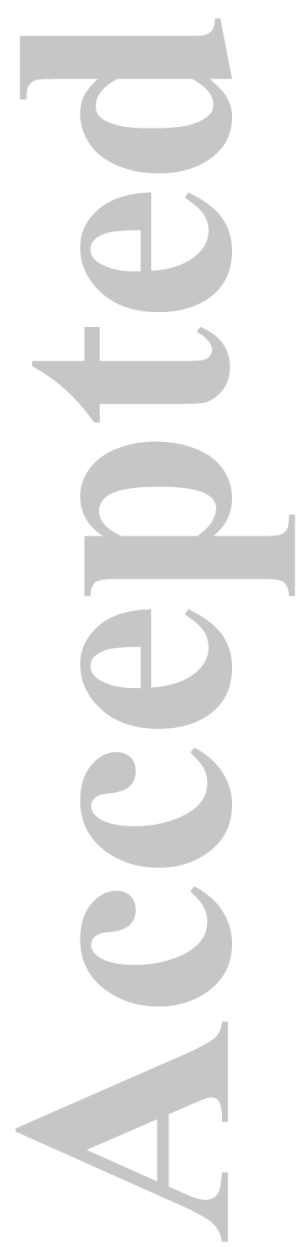



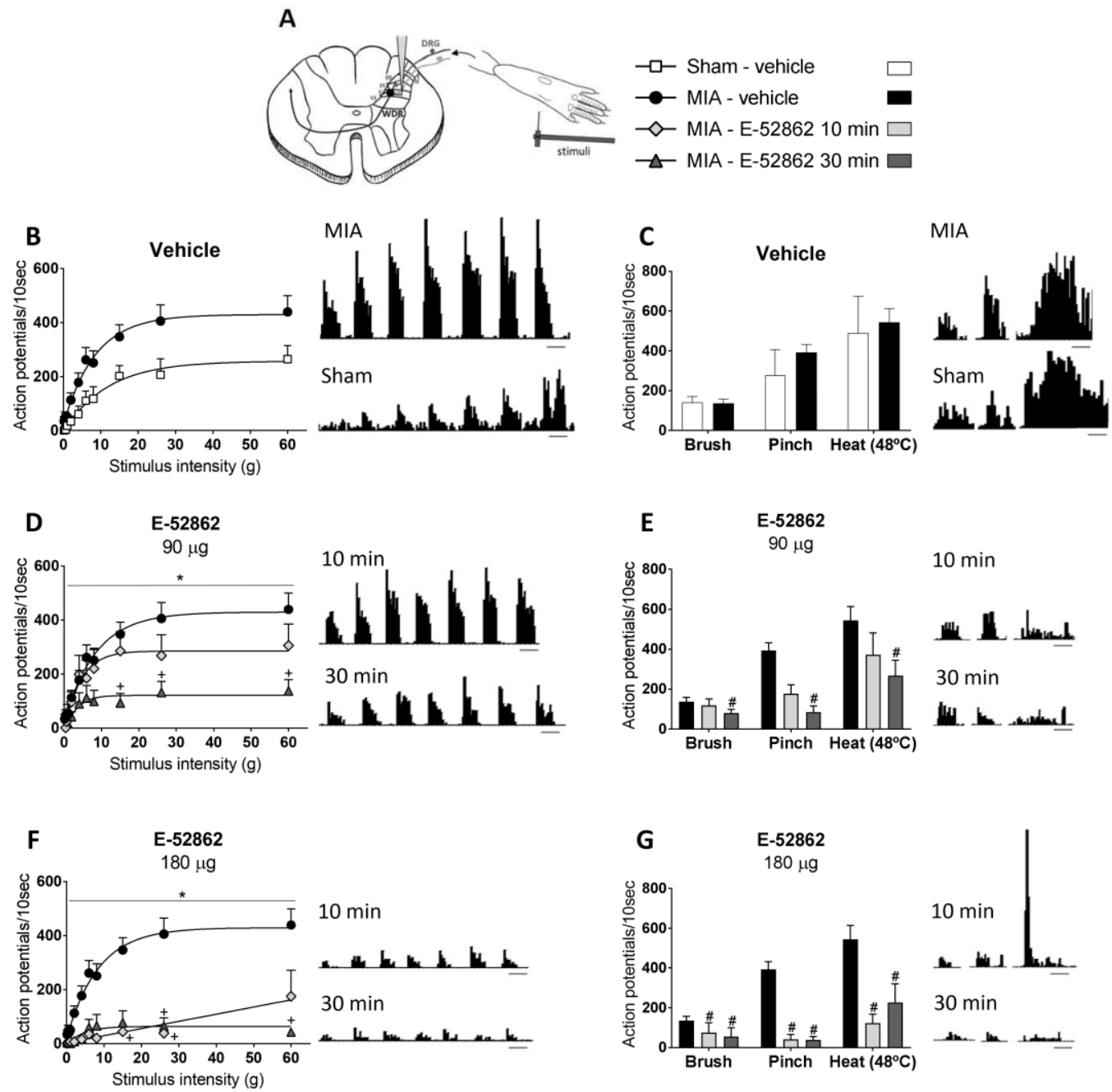

Figure 3. E-52862 reduces osteoarthritis pain-facilitated firing frequency of WDR spinal neurons. (A)

Extracellular recordings were assessed from ipsilateral WDR neurons in the lamina 5 of the dorsal horn. The receptive field in the hind paw was stimulated using von Frey filaments, dynamic brush, static pressure [pinch] and heat [48으. (B) MIA injection facilitated the evoked responses to punctate mechanical stimuli. (C) Firing frequency evoked by brush, pinch or heat was similar in MIA and shaminjected animals. (D, E) $90 \mu \mathrm{g}$ of E-52862 significantly reduced the evoked responses to mechanical and thermal stimuli 30 min after intrathecal application in mice with osteoarthritis pain. $(\mathbf{F}, \mathbf{G})$ Application of $180 \mu \mathrm{g}$ of E-52862 inhibited the firing frequency in response to stimulation of the hind paw 10 and $30 \mathrm{~min}$ after administration. Stimuli were applied for $10 \mathrm{sec}$ and responses are presented 
as mean \pm SEM. Histogram traces for single unit responses of WDR neurons representative for each group are presented. The number of animals is the following: sham-vehicle $=4 ; \mathrm{MIA}$-vehicle $=8 ; \mathrm{MIA}-$ E-52862 $(10$ and $30 \mathrm{~min})=6$. Panels D and F: ${ }^{*}$ for MIA-E-52862 (10 and $\left.30 \mathrm{~min}\right)$ vs. MIA-vehicle (Ftest of non-linear regression), and + for MIA-E-52862 vs. MIA-vehicle (2-way repeated-measures ANOVA plus Fisher least significant difference test). Panels E and G: \# for MIA-E-52862 vs. MIA-vehicle (2-way repeated-measures ANOVA plus Fisher least significant difference test). MIA, monoiodoacetate; SEM, standard error of the mean.

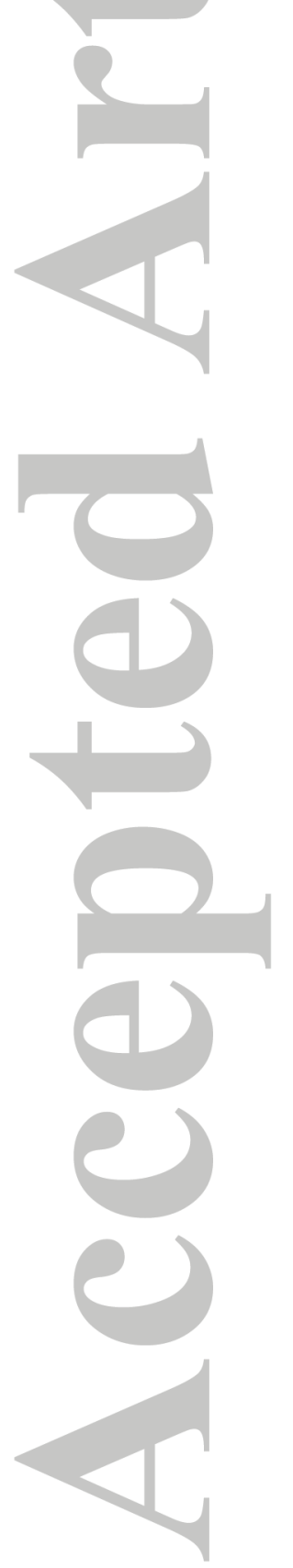



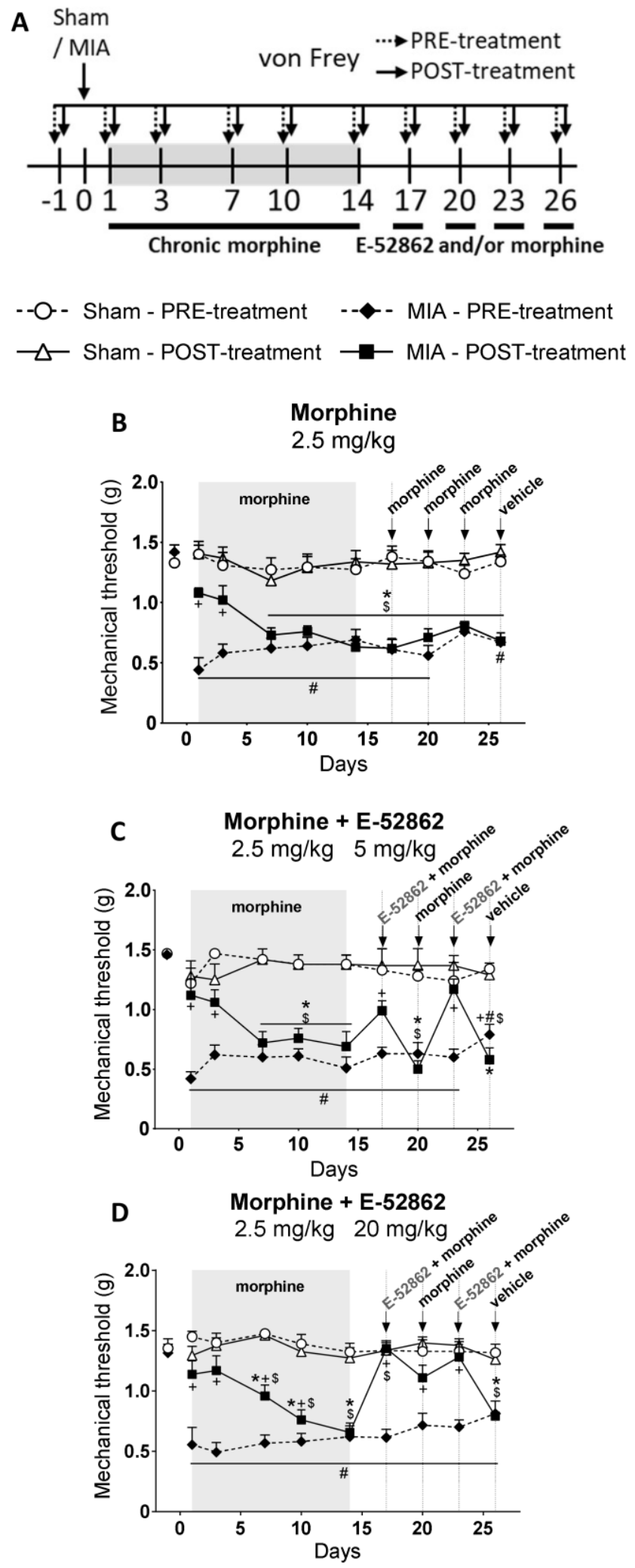

This article is protected by copyright. All rights reserved. 
Figure 4. A single administration of the $\sigma 1 R$ antagonist restores morphine analgesia in opioidtolerant mice. (A) After a 14-day treatment with morphine $(2.5 \mathrm{mg} / \mathrm{kg}$, twice a day during 14 days), mice received acute administrations of morphine $(2.5 \mathrm{mg} / \mathrm{kg})$, E-52862 (5 - $20 \mathrm{mg} / \mathrm{kg})$, or combinations of both drugs. (B, C, D) Mice repeatedly treated with the opioid developed analgesic tolerance. (B) The antinociceptive effect of morphine was not recovered for at least 9 days after the end of the repeated treatment. Single sub-effective $(5 \mathrm{mg} / \mathrm{kg})$ (C) and effective doses $(20 \mathrm{mg} / \mathrm{kg}$ ) (D) of E-52862 combined with morphine produced a restoration of opioid analgesia in morphine-tolerant mice. Mechanical thresholds expressed as mean \pm SEM. The number of animals is (first value represents sham groups and second value represents MIA groups): (B) 8,8 ; (C) 8,8 ; (D) $8,10 .{ }^{*}$ for MIA-POST vs. Sham-POST; \# for MIA-PRE vs. Sham-PRE; + for MIA-PRE vs. MIA-POST; \$ for MIA-POST vs. MIA-POST at day 1 (3-way repeated-measures ANOVA plus Fisher least significant difference test). MIA, monoiodoacetate; SEM, standard error of the mean.

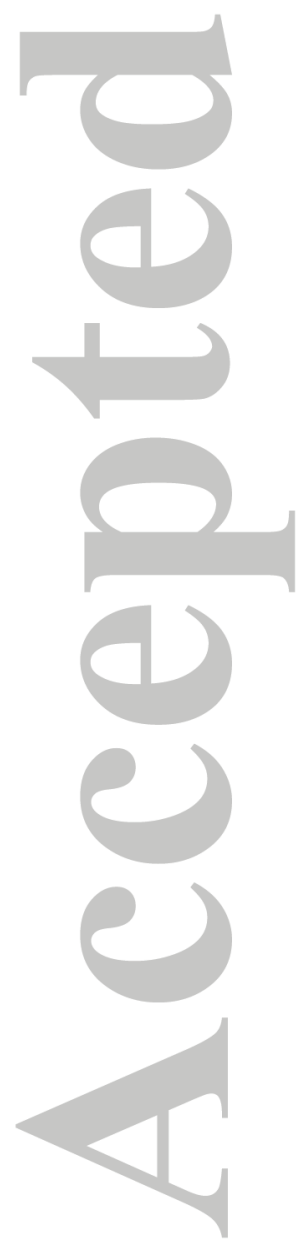


A
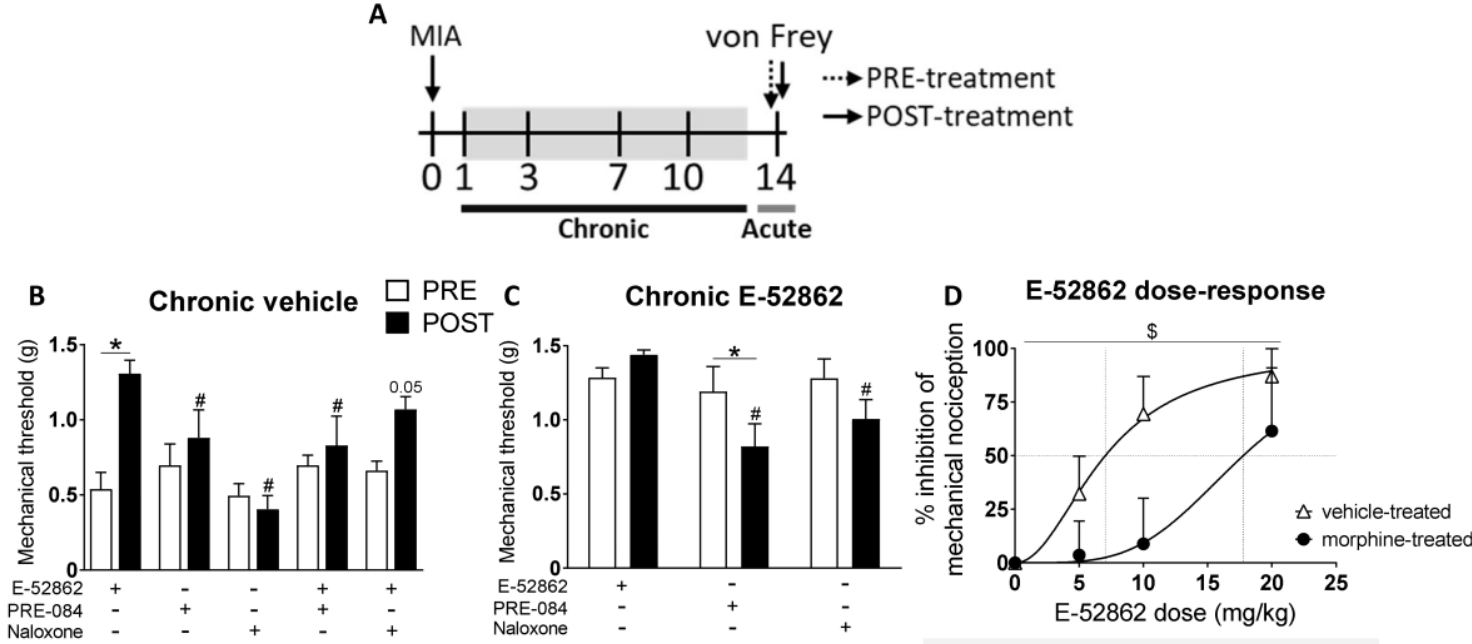

$\mathrm{ED}_{50}$ (vehicle-treated) $=7.03 \pm 1.45 \mathrm{mg} / \mathrm{kg}$ $\mathrm{ED}_{50}$ (morphine tolerant) $=\mathbf{1 7 . 7 7} \pm 3.43 \mathrm{mg} / \mathrm{kg}$

Figure 5. MOR participates in the antiallodynic effect of E-52862. (A) Osteoarthritic mice were treated with vehicle (0.5\% HPMC), E-52862 (20 mg/kg) or morphine $(2.5 \mathrm{mg} / \mathrm{kg}$, twice a day during 14 days). The last day of treatment, mice received acute doses of E-52862 $(5-20 \mathrm{mg} / \mathrm{kg})$, PRE-084 $\mathrm{mg} / \mathrm{kg})$, naloxone $(1 \mathrm{mg} / \mathrm{kg}$ ) or combinations of these drugs. (B) Acute E-52862 $(20 \mathrm{mg} / \mathrm{kg})$ showed reduced anti-allodynic effect when co-administered with PRE-084, and a trend towards a decreased antinociception when given together with naloxone. (C) Once mechanical allodynia was normalized after chronic E-52862, acute administration of PRE-084 and naloxone induced reduction of the mechanical thresholds. (D) E-52862 administered to morphine-tolerant mice showed reduced antinociceptive effects. Data are expressed as mean \pm SEM. The number of animals is: (B) 6 per group; (C) 6 per group; (D) 8 for vehicle-treated, 6 for morphine-treated. For panels B and C: * for PRE vs. POST; \# vs. E-52862 POST (2-way repeated measures ANOVA plus Fisher least significant difference test). For panel D: \$ for vehicle-treated vs. morphine-treated (F-test of non-linear regression). MOR, mu opioid receptor; MIA, monoiodoacetate; SEM, standard error of the mean.

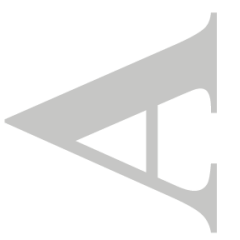



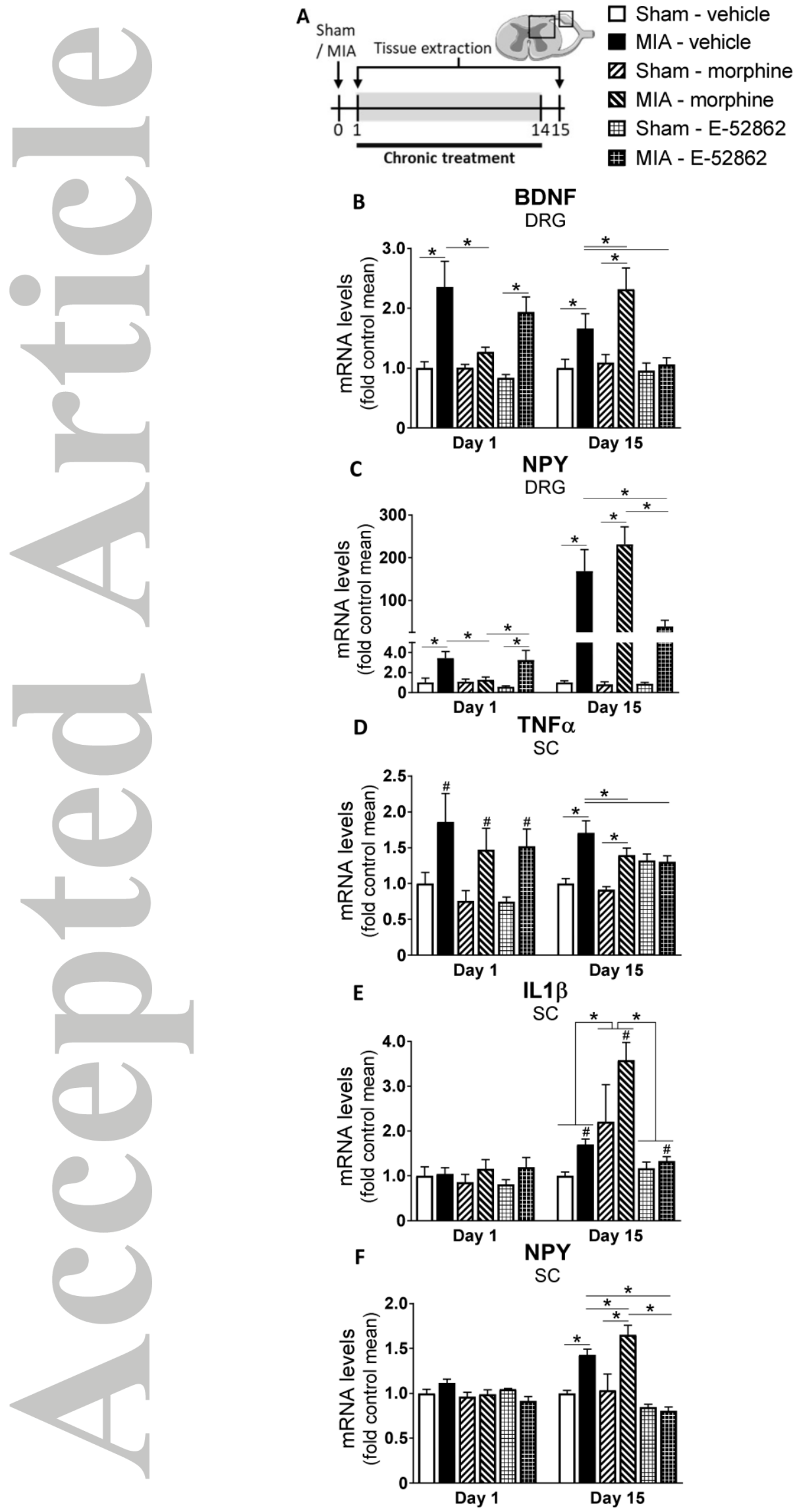

This article is protected by copyright. All rights reserved. 
Figure 6. Repeated E-52862 reduces the expression of neuroinflammatory mediators associated with osteoarthritis pain and chronic morphine administration. (A) Spinal cord and DRG were extracted 1 or 15 days after sham or MIA injection from mice treated with vehicle (0.5\% HPMC), morphine $(2.5 \mathrm{mg} / \mathrm{kg})$ or E-52862 $(20 \mathrm{mg} / \mathrm{kg})$. The first day after the intra-knee injection, MIA induced over-expression of BDNF (B) and NPY (C) in the DRG, which were reduced by the acute administration of morphine. In the spinal cord, MIA-injected mice showed increased levels of TNF $\alpha$ (D), whereas IL1 $\beta$ (E) and NPY (F) were not altered. 15 days after MIA or sham injection, BDNF (B) and NPY (C) in the DRG, and spinal TNF $\alpha$ (D), IL1 $\beta$ (E) and NPY (F) were increased in osteoarthritic mice and normalized by $E-52862$ chronic treatment. Morphine treatment further increased expression of BDNF (B), IL1ß (E) and spinal NPY (F). Data are expressed as mean \pm SEM. The number of animals is the following: day 1 = 5 per group; day 15 = 6 per group. \# for MIA vs. sham (2-way ANOVA followed by Fisher least significant difference test for each time-point). BDNF, Brain derived neurotrophic factor; DRG, dorsal root ganglia; IL1 $\beta$, interleukin-1 beta; MIA, monoiodoacetate; NPY, neuropeptide Y; SC, spinal cord; SEM, standard error of the mean; TNF $\alpha$, tumor necrosis factor alpha.

This article is protected by copyright. All rights reserved. 

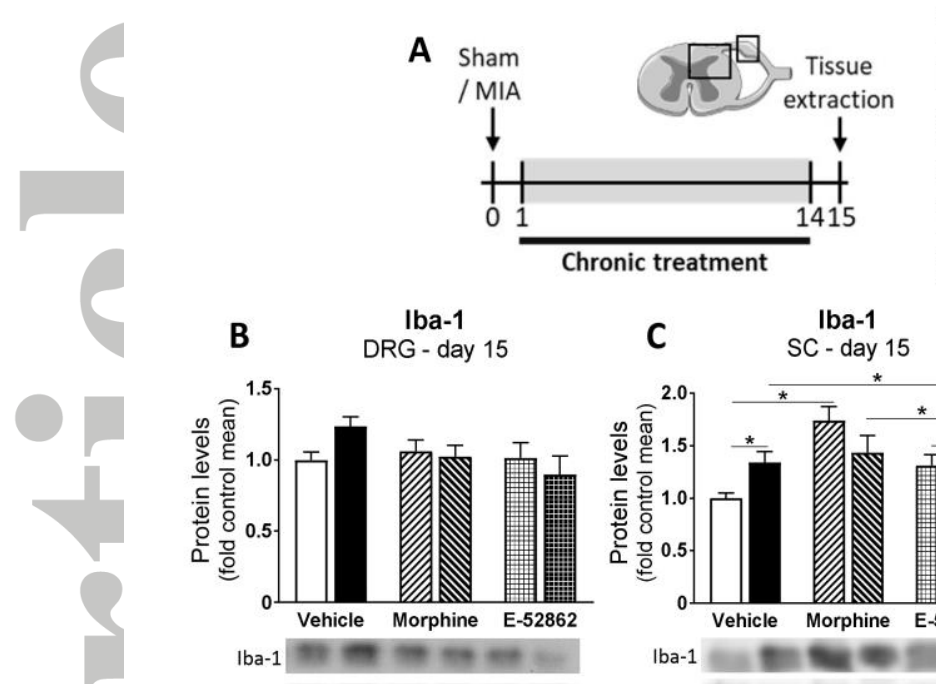

GAPDH $m m-m=$

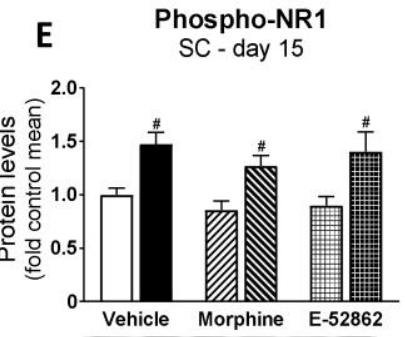

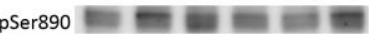

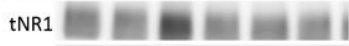

GAPDH
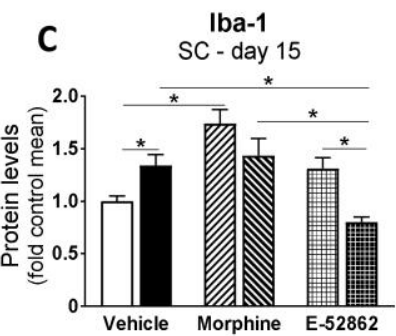

Iba-1

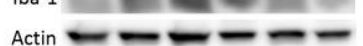

F $\begin{gathered}\text { Phospho-NR2B } \\ \text { SC - day } 15\end{gathered}$

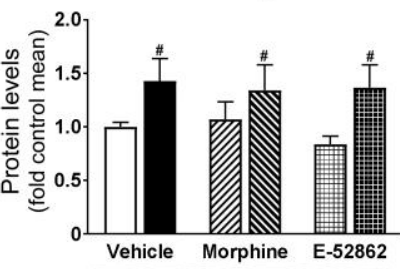

pTyr1472 - N

tNR2B $=$

Actin -----
Sham - vehicle

MIA - vehicle

U Sham - morphine

N MIA - morphine

团 Sham - E-52862

MIA - E-52862

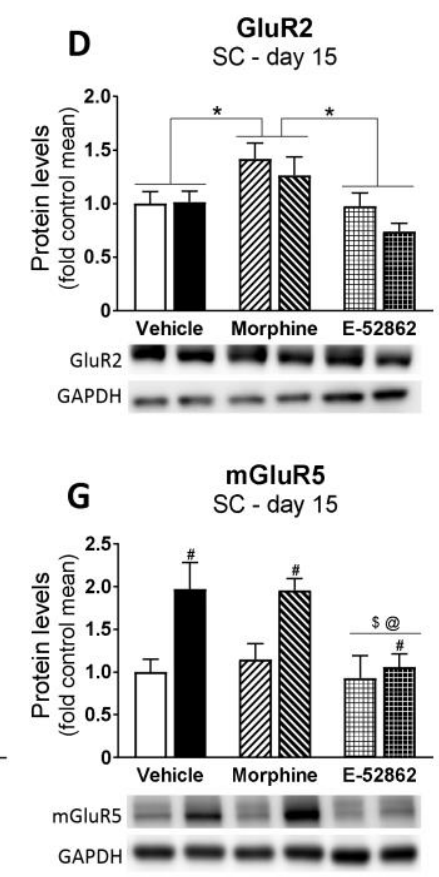

Figure 7. Repeated treatment with E-52862 decreases pain-induced microgliosis and mGluR5 up-

regulation. (A) 15 days after sham or MIA injection, spinal cord and DRG were extracted from vehicle (0.5\% HPMC), morphine $(2.5 \mathrm{mg} / \mathrm{kg})$ or E-52862 $(20 \mathrm{mg} / \mathrm{kg})$-treated mice. (B) Protein levels of Iba-1 showed no significant differences in the DRG. (C) At spinal level, lba-1 was increased after MIA or chronic morphine and reduced by E-52862. (D) Morphine induced an up-regulation of GluR2 AMPA receptor subunit. Phosphorylation levels of NR1 (E) and NR2B subunits (F) of the NMDA receptor were increased after MIA injection regardless of the treatment received. (G) MIA injection significantly increased the protein levels of mGluR5, which were reduced after E-52862. GAPDH or Actin were used as a housekeeping control. Data are expressed as mean \pm SEM. The number of animals is 6 per group. \# for MIA vs. sham; \$ for E-52862 vs. Vehicle; @ for E-52862 vs. Morphine (2-way ANOVA followed by 
Fisher least significant difference test). MIA, monoiodoacetate; SC, spinal cord; DRG, dorsal root ganglia; SEM, standard error of the mean; pSer890, phosphorylation of Serine 890 of the NR1 subunit of the NMDA receptor; tNR1, total NR1 subunit; pTyr1472, phosphorylation of Tyrosine 1472 of the NR2B subunit of the NMDA receptor; tNR2B, total NR2B subunit.

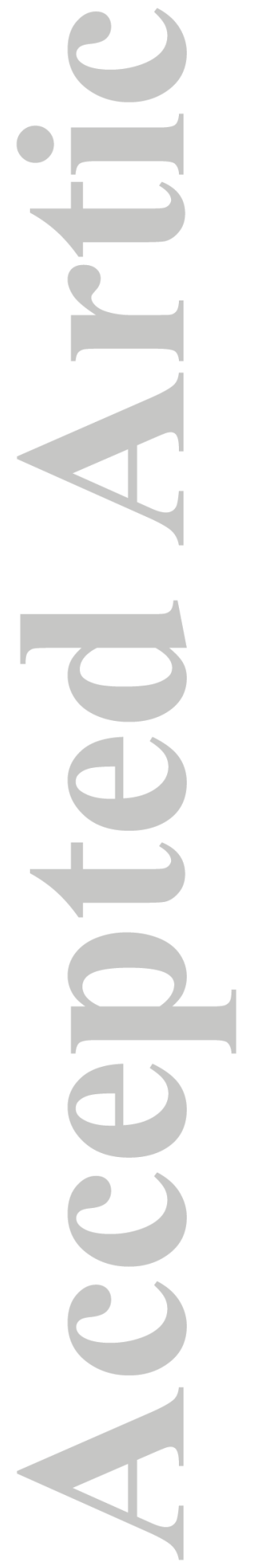

